\title{
زواج التجربة: تكييفه الفقهي وأحكامه
}

\section{بندر بن صقر بن سالم الذيابي}

أستاذ مشارك- قسم الشريعة- كلية الشريعة والأنظمة- جامعة تبوك- السعودية balthiabi@ut.edu.sa 


\section{زواج التجربة: تكييفه الفقهي وأحكامه \\ بندربن صقربن سالم الذيابي \\ أستاذ مشـارك- قسم الشريعة- كلية الشريعة والأنظمة- جامعة تبوك- السعودية \\ balthiabi@ut.edu.sa}

DOI: https://doi.org/10.31559/SIS2021.6.3.4 2021/11/11 2021/10/9 مراجعة البحث: 2021/10/24 قبول البحث البحث: 2010

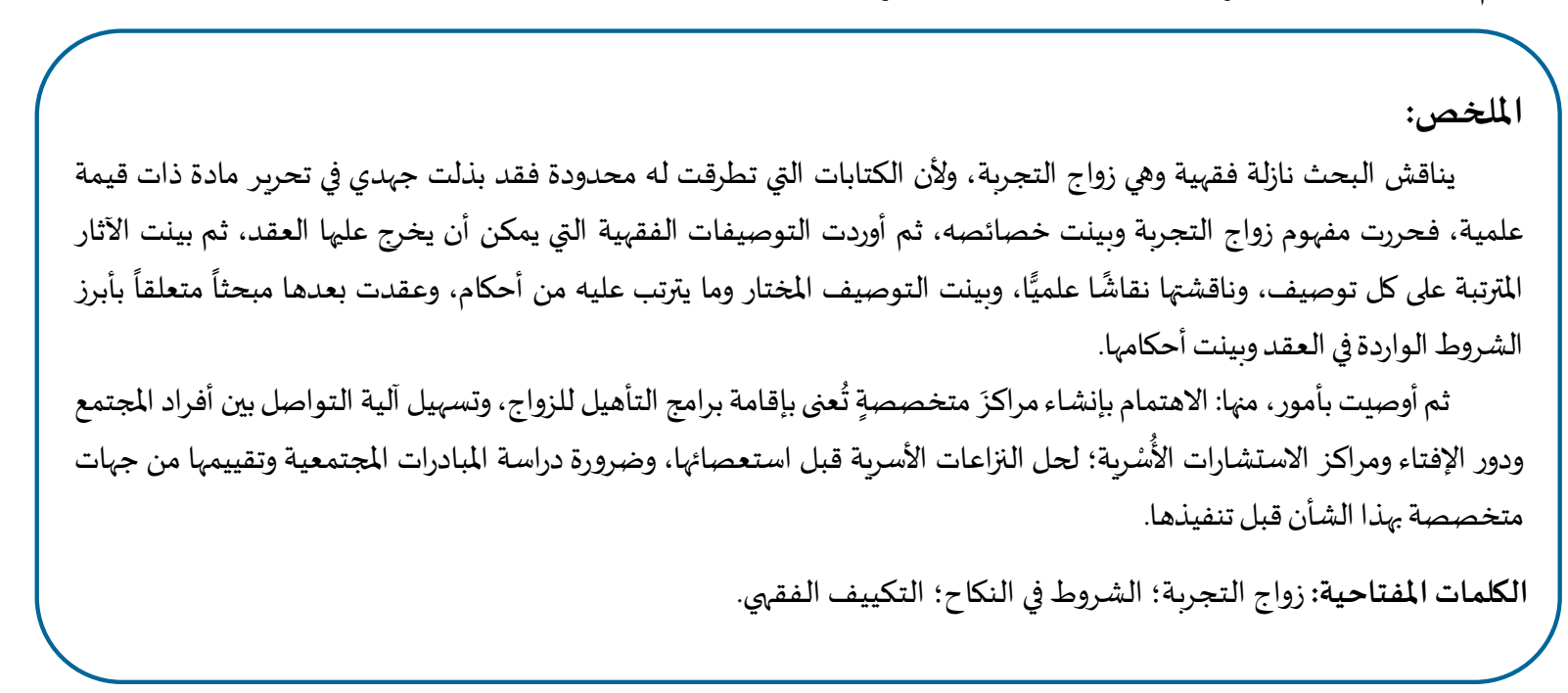

المقدِّمة:

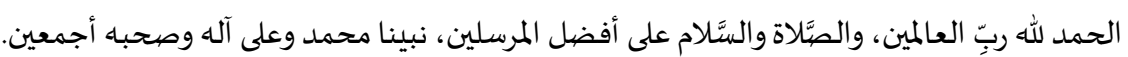

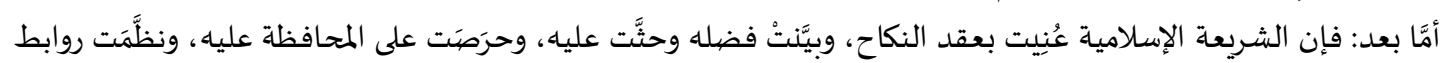

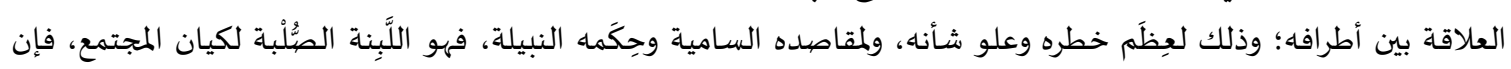

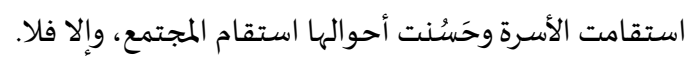

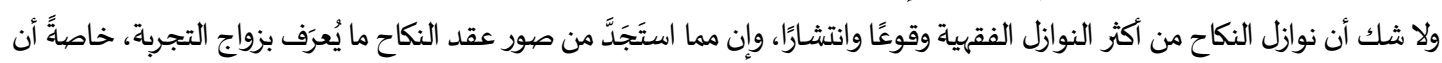

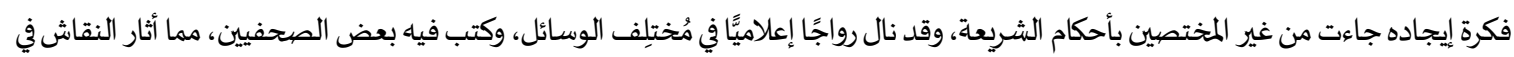

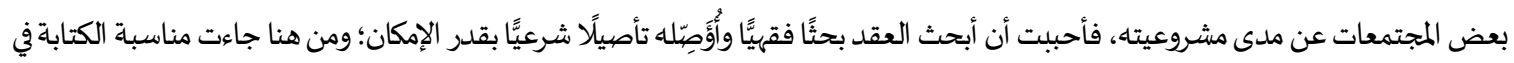
الموضوع الموسوم ب"زواج التجربة: تكييفه الفقهي وأحكامه".

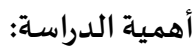

تتجلى أهمية الموضوع في الآتي:

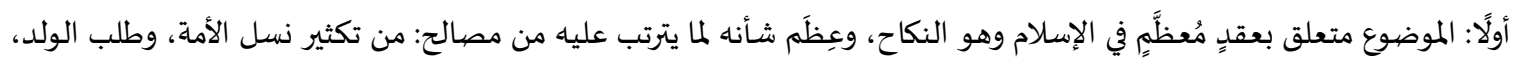

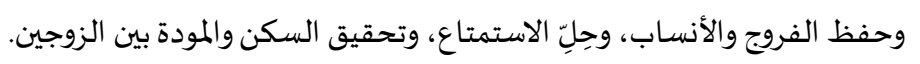

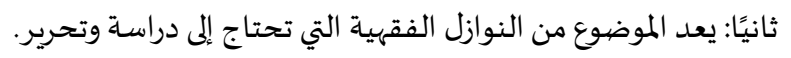

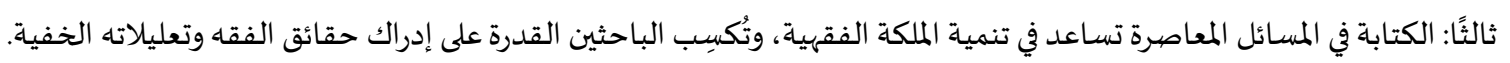


أسبباب اختيار موضهوع الدراسة:

1. نشأت فكرة العقد- من غير المختصين بالشريعة -بقصد معالجة النزاعات الأُسنرية والقضياء على أسباب الخلافات الزوجية، إلا

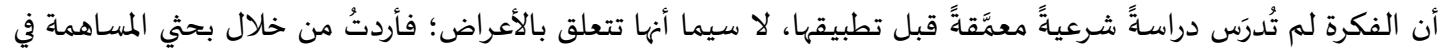
تحرير صورة العقد ودراسته دراسةً فقهيةً.

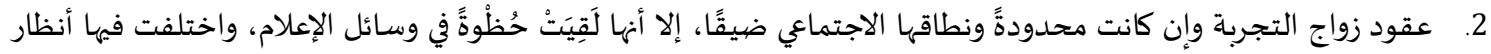

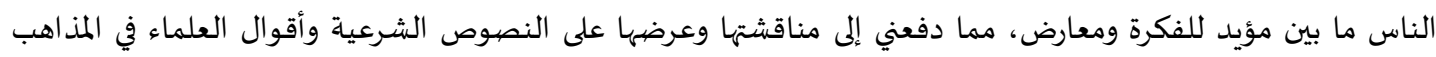
الفقهيية. 3. عقد زواج التجربة يدخل ضمن اهتماماتي البحثية والأكاديمية، فقد كتبتُ بحثًا بعنوان: (أثر الأمراض الجلدية على النكاح)،

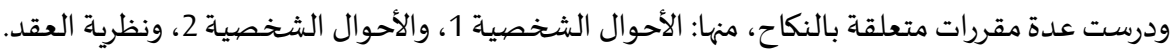

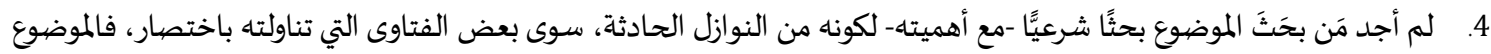
بحاجة إلى دراسـة لتحرير جوانبَ متعددةٍ منها.

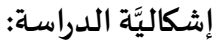

تكمن إشكالية البحث في أنه من المُستجدِّات الفقهية، وهو بحاجة إلى دراسة مؤصلة لبيان تكييفاته الفقهية والآثار المترتبة عليها. فالبحث يجيب عن تساؤلات، ويناقش آراءً، في ضيوء النِّقاط الآتياة:

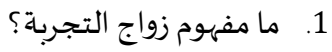

$$
\begin{aligned}
& \text { 2. ما التكييفات المحتملة لعقد زواج التجربة ؟ ماتج }
\end{aligned}
$$

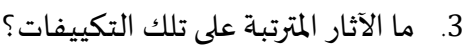

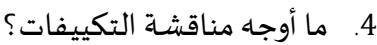

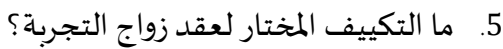

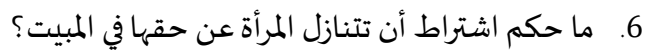

7. ما حكم اشتراط أحد الزوجين على الآخر السماح لله بالاطلاع على معلوماته الخاصية؟

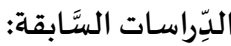

يعد موضوع زواج التجربة من الموضهوعات المُستجدِّة، ومن هنا فإني لم أجد مَن كتب في الموضوع كتابةً فقهيّةً، ومنتهى ما وجدت بعض الفتاوى، وأبرزها:

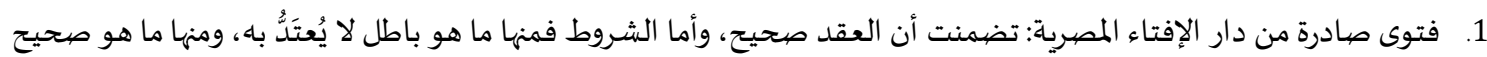
يَلزَرُ الوفاءُ بـه.

2. فتوى مركز الأزهر العالمي للفتوى: وتضمنت أن اشتراط انتهاء عقد الزواج بانهاء مدة معينة يجعل العقد باطلًا ومحرمًا، وأن

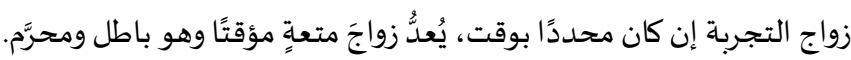
وقد بذلت جهدًا في الإلمام بالموضوع من جوانبه المتعددة، وتوسعت في بياناه من حيث المفهوم والتكييفات الفقهية المحتملة

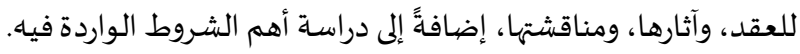

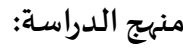

اعتمدت في كتابة البحث على المناهج الآتية:

1. المنهج الاستقرائي والوصفي التحليلي: بإيراد التكييفات الفقهية المحتملة للعقد، وتوضيحها، وعزوها إلى القائلين بها، وحجة كل قول، وبيان الآثار المترتبة على التكييف. 2. المنهج الجدلي: بالتخريج على الأقوال الفقهية، ومناقشة كل تخريج، والوصول إلى التخريج المختار، والرد على أوجه الاعتراض وسأبذُل الوُسنحَ -بعون الله- في كتابة البحث في ضوءِ الخُطُوات الآتية: بيان التكييف الفقهي، ومن قال باه، وحجة قائليه، والآثار المترتبة عليه، ومناقشتهـ.

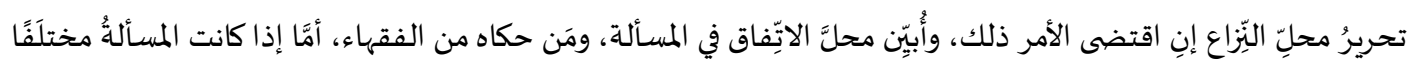

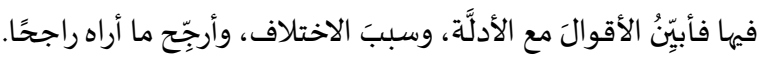

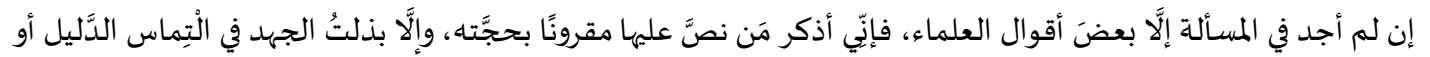


بيان أوجاه الاعتراض.

$$
\text { بيان موضع الآيات من السُّور. }
$$

تخريج الأحاديث الواردة في البحث من كتب الحديث، والحكم عليها من كلام المحدِّينين، ما لم تكن في 》الصَّحيحينه أو

أحدهما، فأكتفي بذلك.

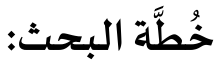

يتكوَّن البحث من: مقدمة، وتمهيد، وخمساة مباحث، وخاتمة.

المقدِّمة تشتمل على:

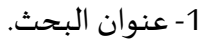

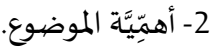

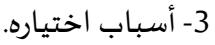

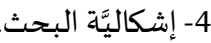

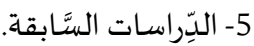

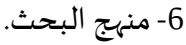

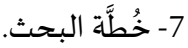

التمهيد: وفياء ثلاثة فروع:

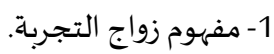

2- خصيائص زواج التجربة.

3- مشروعية النكاح.

المبحث الأوَّل: تكييفهاه على أنهاء عقد صحيح مشتمل على شروط معتبَرة، وفيه ثلاثة مطالب:

المطلب الأوَّل: بيان التكييف. لمبيد.

المطلب الثَّاني: الآثار المترتبة على التكييف.

المطلب الثالث: مناقشة التكييف.

المبحث الثَّاني: تكييفه على أنهاء عقدُ صهُلْح، وفيهاء ثلاثة مطالب:

المطلب الأوَّل: بيان التكييف.

المطلب الثَّاني: الآثار المترتبة على التكيفيف التكيف.

المطلب الثالث: مناقشة التكييف.

المبحث الثالث: تكييفه على أنه عقدُ مُتْعِةٍ وفيهاه ثلاثة مطالب:

المطلب الأوَّل: بيان التكييف. لماند.

المطلب الثَّاني: الآثار المترتبة على التكييف.

المطلب الثالث: مناقشة التكييف.

المبحث الرابع: التكييف المختار (العقد صحيح والشرط باطل)، وفياء مطلبان:

المطلب الأوَّل: بيان التكييف: التحيد.

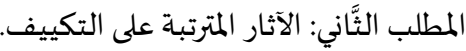

المبحث الخامس: الشروط الجزئية الواردة في العقد، وفيه مطلبان:

المطلب الأوَّل: اشتراط أن تتنازل المرأة عن حقها في المبيت، وفياه فرعان:

الفرع الأول: صبورة الشرط.

الفرع الثاني: حكم الشرط.

المطلب الثاني: اشتراط أحد الزوجين على الآخر السماح له بالاطلاع على معلوماته الخاصية، وفيه فرعان:

$$
\text { الفرع الثالثال: صورة الشرط. }
$$

الخاتمة: وتشتمل على أهمِّ النَّتائج والتَّوصِيَات. 


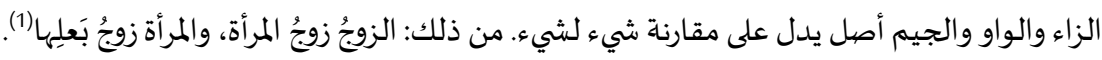

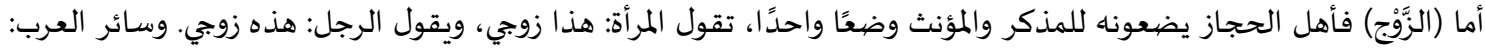

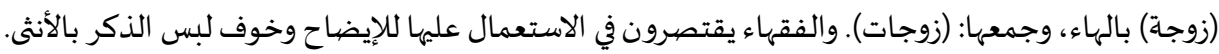

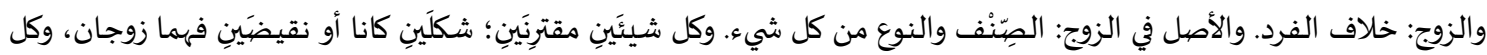

واحد منهما زوج( (2). أما الزواج في الاصطلاح؛ فالمراد با: النكاح، واختلفت عباراتهم في ماهية النكاح.

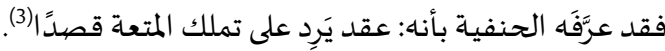

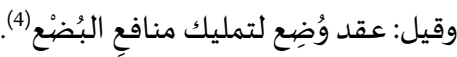

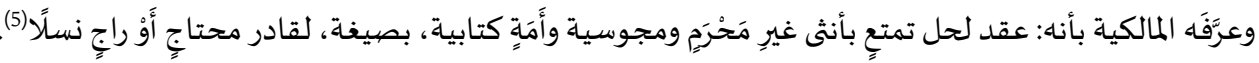

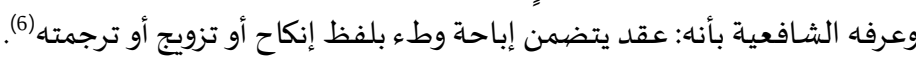

وعرفه الحنابلة بأنها:عقد التزويج(7).

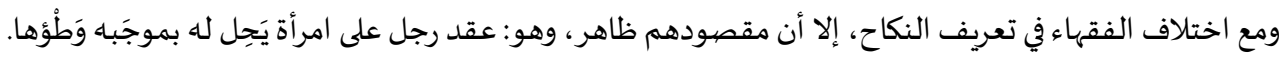

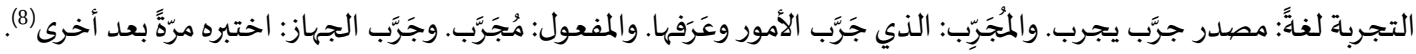

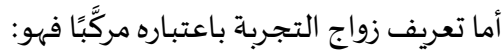

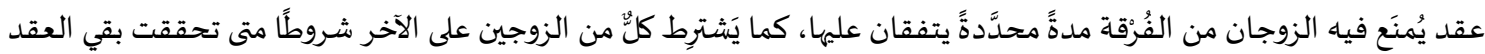

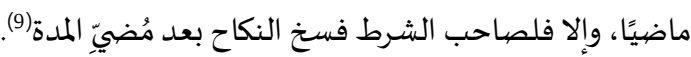

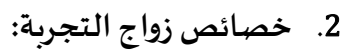

ومن هنا يلاحَظ أن عقد زواج التجربة يتميز عن غيره من أنواع الأنكحة بالآتي:

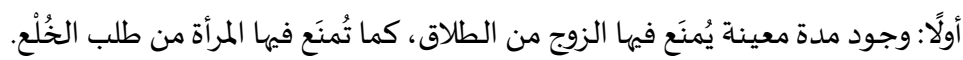

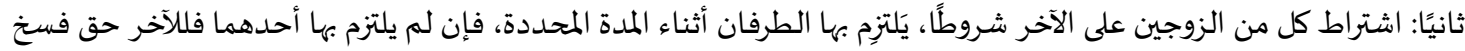
النكاح بعد انتهاء المدة.

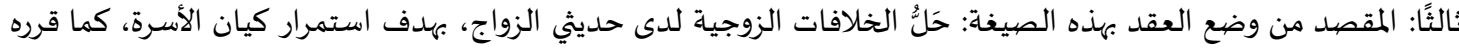
أصحاب فكرة زواج التجربة(10).

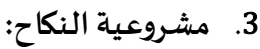

$$
\text { النكاح مشروع، والأصل في مشروعيته الكتاب والسنة والإجماع: }
$$

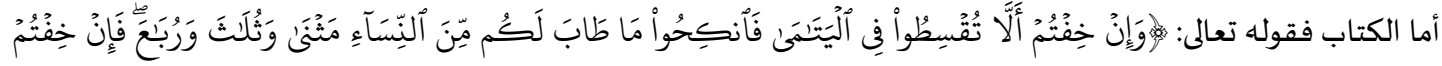

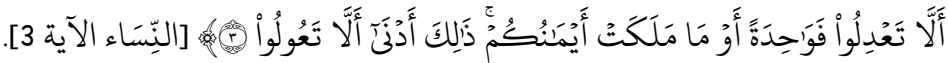
وأما السنة فقول النبي صلى الله عليه وسلم: ايا معشر الشباب، من استطاع منكم الباءة فليتزوَّج؛؛ فإنه أغضُّ للبصر، وأَحصَنُ 


$$
\begin{aligned}
& \text { للفرج، ومن لم يستطع فعليه بالصوم، فإنها له وِجاءه|(11). } \\
& \text { أما الإجماع فحكاه جماعة من أهل العلم. }
\end{aligned}
$$

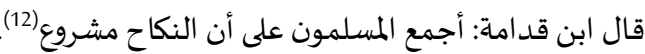

وقال الماوردي: أباح الله تعالى النكاح نصًّا في كتابه، وصريحا في سنة نبل نبيه صلى الله عليه وسلم، وانعقد بها سالف إجماع الأمة (13).

\section{المبتحث الأوَّل: تكييفه على أنه عقد صحيح مشتمل على شروط معتبَرة}

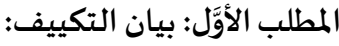

ذهب بعضُ مَن يرى صحة زواج التجربة إلى أنه عقد صحيح كبقية أنواع الأنكحة المباحة شرعًا؛ لأن الأصل في العقود الصحةدة،

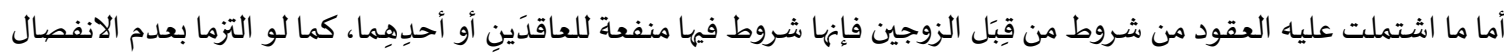

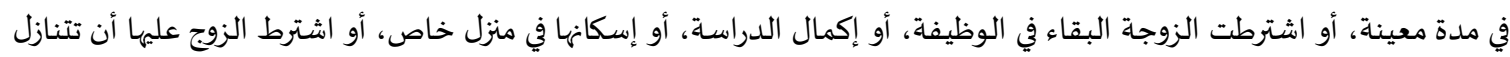

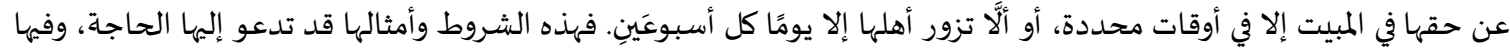

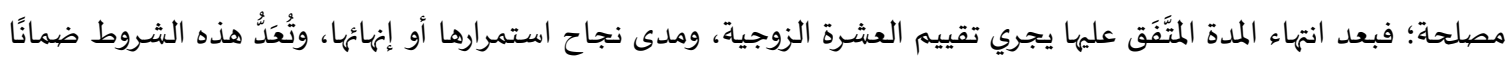

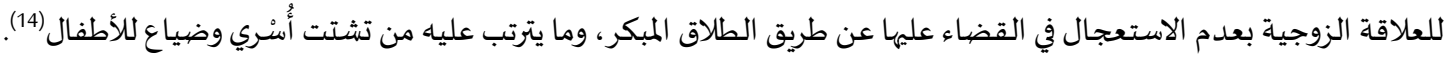

$$
\text { المطلب الثَّاني: الآثار المترتبة على التكييف: }
$$

$$
\text { مما يترتب على هذا التكييف الآتي: }
$$

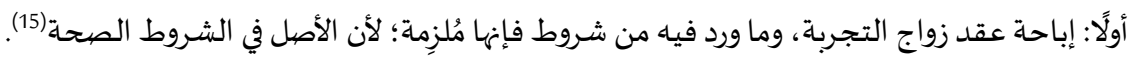
ثانيًا: مطالبة من حرَّم زواج التجربة بالدليل.

$$
\text { المطلب الثالث: مناقشة التكييف: }
$$

$$
\text { هذا التكييف ضعيف من وجوه، أبرزها: }
$$

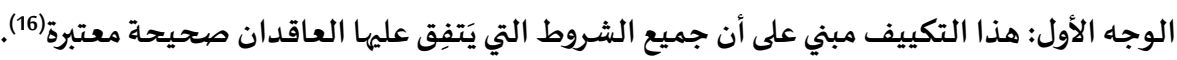

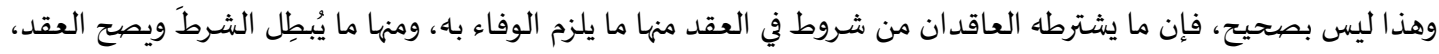

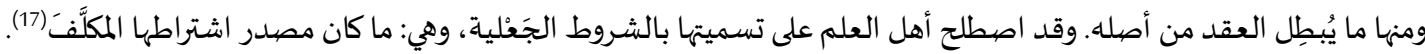
والشروط الجعلية تنقسم إلى قسمَينِ: 1. شرط معلَّق: وهو ما يُنكَر بصيغة التعليق، مثل: (إنْ) أو إحدى أخواتها. مثاله: إنْ دخلتِ الدار فأنت طالق، فيلزم الطلاق بالدخول. 2. شرط مقيد: أن يقترن العقد بالتزام أحد الطرفَينِ بالوفاء بأمر زائد على أصل التصرف غير موجود وقت التعاقد(18).وهذا النوع هو محل البحث. والشروط الجعلية المقيدة في عقد النكاح تنقسم إلى أربعة أقسام باعتبار صِحَِّها: أولًا: الشروط المو افِقة لمقتضى العقد: وهي الشروط التي تتم على أحكام الشرع، مثل: أن تشترط الزوجة نفقتها على الزوج، أو تشترط عليه حُسنَّ العشرة، وأن يَكُشُوَها

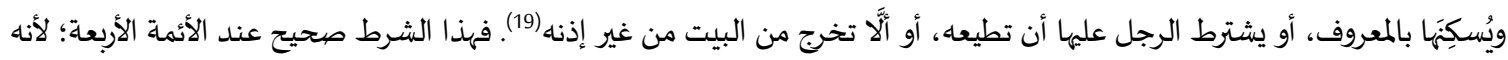
11 متفق عليه من حديث عبد الله بن مسعود رضبي الله عنه، رواه البخاري في صحيحه، كتاب النكاح، باب: من لم يستطع الباءة فليصم، رقم (5066)، ومسلم في صحيحها، كتاب

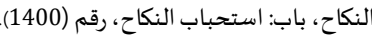
12 ينظر: المغني (4/7). 13 ينظر: الحاوي الكبير (12/9).

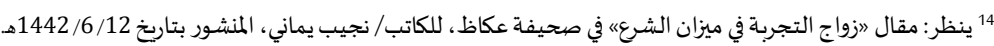

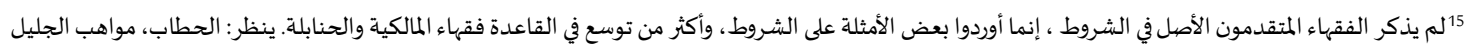

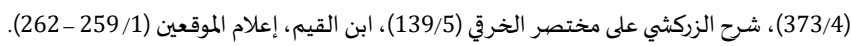

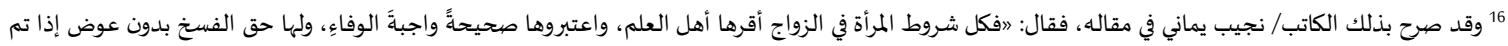
مخالفة الشروط «. ينظر: المرجع قبل السابق.

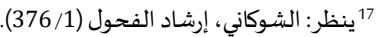


المقصود من العقد(20).

ثانيًا: الشروط التي فيها مصيلحة للعقد:

كما إذا عقد النكاحَ ولم يدفع المهر، واشترط عليه كفيلًا. فهذا صحيح أيضًا عند الأئمة الأربعة؛ لأنها يؤدي إلى إتمام العقد

والتوثق منـه(21).

ثالثًا: الشروط المناقضية أو المنافية للعقد:

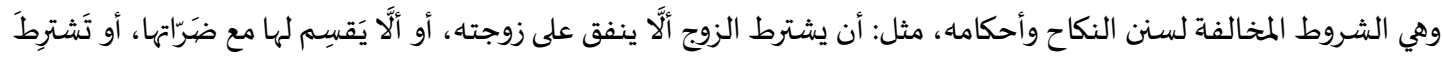

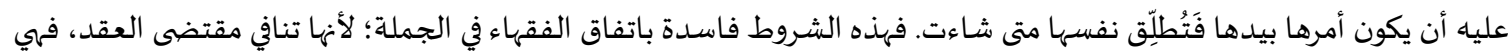
تتضمن إسقاط حقوق تجب بالعقد قبل انعقاده. ويصح العقد؛ لأن هذه الشروط تعود لمعنى زائد في العقد لا يُشترَط ذكره، ولا يضر الجهل باه، فلم يبطله (22).

رابعًا: اشتراط الزوجَيِن أو أحدهما منفعةً معلومةً لا يقتضيهها العقد ولا تخالف مقتضشاه:

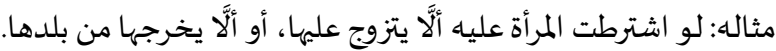

وهذا القِِنْم محل اختلاف بين الفقهاء، وتباينت تفريعاتهم حياله، والخلاف هنا راجع إلى اختلافهم في الأصل في الاشتراط: هل

الأصل فياه الحظر أو الإباحة؛ مجدي

فمذهب الظاهرية: أن الأصل في الاشتراط الحظر. ووافقهم على هذا المبدأ الحنفية والمالكية والشافعية إجمالًا (23)، وإن اختلفوا

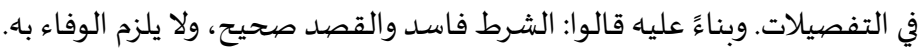
بينما ذهب الحنابلة إلى أن الأصل في الاشتراط الإباحة(24)، ووافقهم على ذلك طائفة من فقهاء المالكية والشافعية(25)، حتى نسباء ابن القيم للى

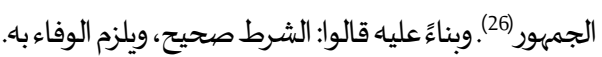

وسبب اختلافهم: معارضة العموم للخصوص، فأما العموم فحديث عائشة رضبي الله عنها، أن النبي صلى الله عليه وسلم خطب ولب

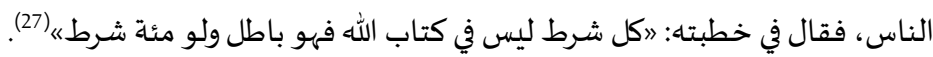

وأما الخصوص فقاص فحديث عقبة بن عامر رضي الله عنه، عن النبي صلى الله عليه وسلم أنه قال: اأحق الشروط أن يُوفّى به: ما

استحللتم باء الفروج《(28).

إلا أن المشهور عند الأصوليين القضياء بالخصوصهو على العموم(29).

الترجيح:

يترجح لي القول بصحة الشروط التي لا يقتضيها العقد ولا تخالف مقتضاه وفيها مصلحة للعاقد، ويلزم الوفاء بها، ومن لم يوفِّ التحِ بالشرط فللطرف الآخر حق الفسخ، ويدل لوجاهته: أن الأدلة التي استدلوا بها وردت خاصةً في محل النزاع؛ بخلاف أدلة الجمهور فهي

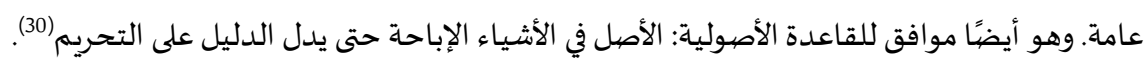
وخلاصة الرد: أن الشروط في عقد النكاح ليست على نحو واحد، بل منها الصحيح ومنها الباطل.

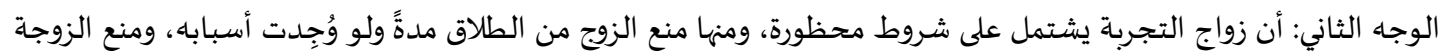
من الخُلْع ولو وُجِد المسبوِغ. وسئل الشيخ ابن باز عن: امرأة اشترطت قبل عقد الزواج على الخاطب أَلَّ يطلقها، وقَبِلَ الزوج هذا الشرط، فهل هذا الشرط صحيح

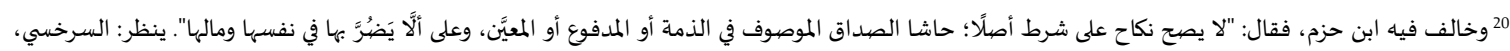

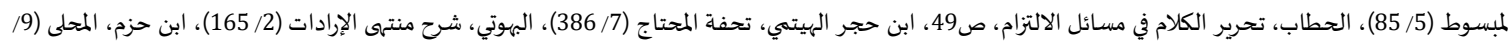

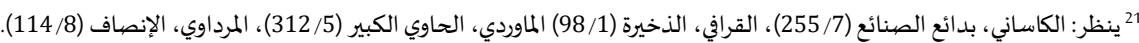

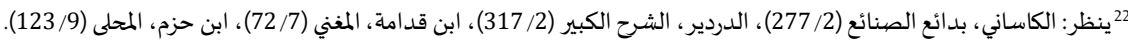

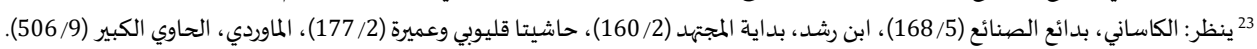

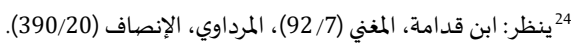

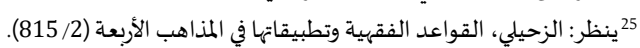
26 ينظر: ابن القيم، إعلام الموقعين (1/ 259 - 25 - 162).

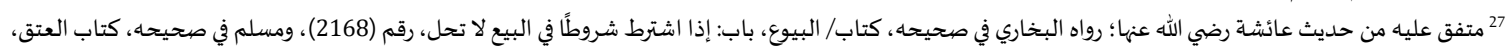

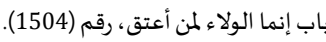
28 متفق عليه من حديث عقبة رضي الله الهن عنه، رواه (1504) البن البخاري في صحيحه، كتاب النكاح، باب: الشروط في النكاح، رقم (5151)، ومسلم في صحيحه، كتاب النكاح، باب: الوفاء بالشروط في النكاح، رقم (1418) من جدئ

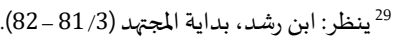
ينظر: السيوطي، الأشباه والنظائر (ص60). 
أم لا؟ وهل يحق للمرأة أن تشترط أن يكون حَلُّ عُقْدةِ النكاح بيدها؟

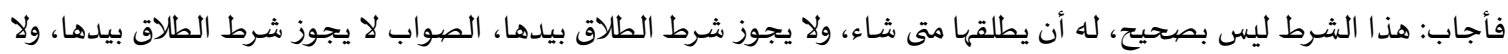
شرط أنه لا يطلقها، يعني: قد تأتي أمور توجب الطلاق، وإذا شرطت ألا يطلقها، فله أن يطلقها، نعم إذا دعت الحاجة إلى طلاقها؛ لأن الشرط غير صحيح (31). وهذا الشرط يتضمن إسقاط حقوق لا تقبل الإسقاط. وقد ذهب جمهور الفقهاء من المالكية (32) والشـافعية(33) والحنابلة(34): إلى

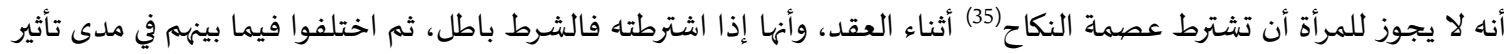

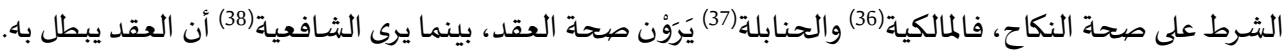

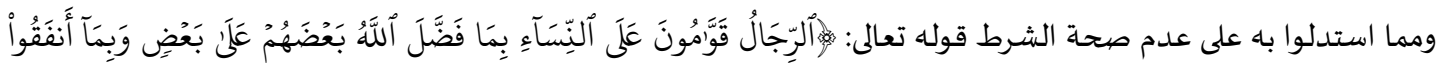

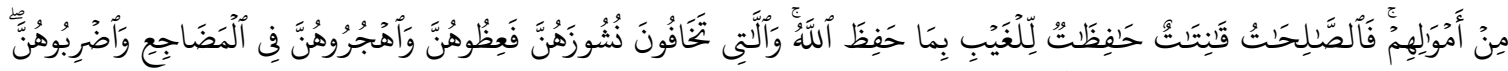

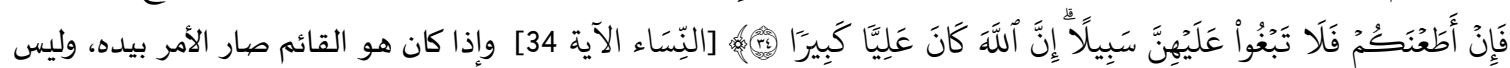
بيدها(39).

وبقول النبي صلى الله عليه وسلم: 》كل شرط ليس في كتاب الله فهو باطل، وإن كان مئة شرط《(40).

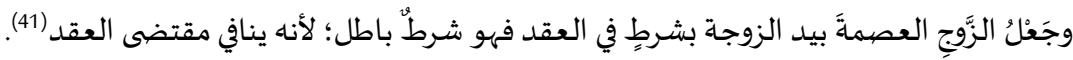

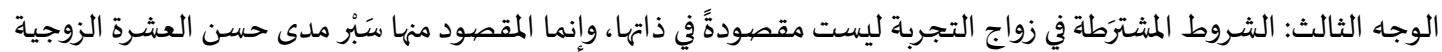

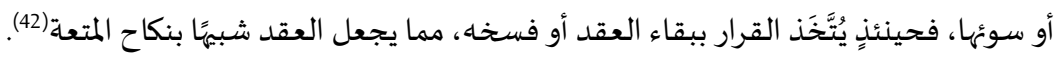

\section{المبتحث الثَّاني: تكييفه على أنه عقد صلح}

المطلب الأوَّلّ: بيان التكييف:

بيانه: يرى المحامي بالنقض/ أحمد مهران، وهو صاحب لاحب فكرة زواج التجربة: أن العقد الذي يحرره هدفه الصلح (43) بين الزوجين،

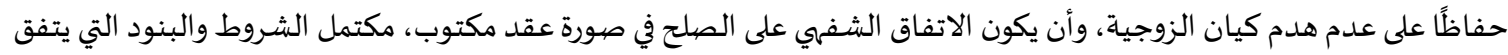
عليها الطرفان. وأن العقد الذي انتشر على مواقع التواصل الاجتماعي هو عقد صلح بعد تقريب وجهات النظر بينهما، وأن شرط

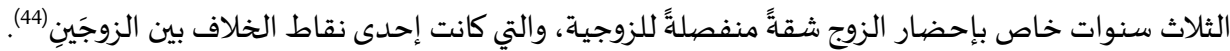
المطلب الثَّاني: الآثار المترتبة على التكييف:

$$
\text { يترتب على هذا التكييف الآتي: }
$$

أولًا: إباحة زواج التجربة؛ لأن عقد الصبلح الأصل فياه أناه مندوب، وقد تأتي عليه الأحكام التكليفية. ونقل صاحب كتاب " امنح الجليل"

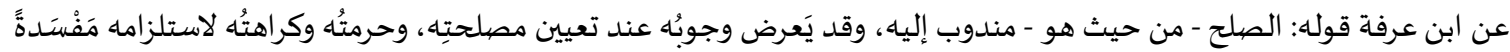

(31 31 ينظر: مجموع فتاوى ابن باز (47/21). 3232 ينظر: العبدري، التاج والإكليل (81/5) (81).

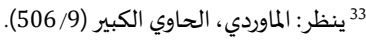

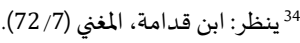

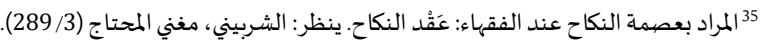

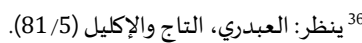

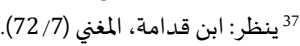
38 ينظر: الماوردي، الحاوي الكبير (506/9 (506). 39 ينظر: فتاوى علماء البلد الحرام ص299 الكير (5296.

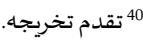

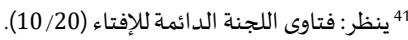

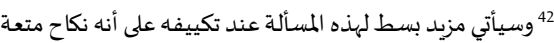

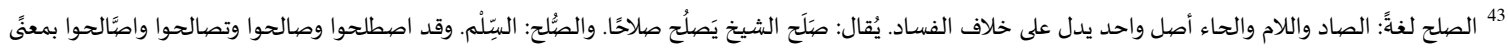


واجبةًَ الدَّزِْْ أو راجحتَّه (45).

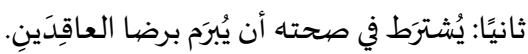

المطلب الثالث: مناقشة التكييف

هذا التكييف لا يصح؛ لوجوه عديدة، منها:

أولًا: أن الصلح لا بد أن تكون فيه دعوى أو خصومة؛ لأن لفظ (الصلح) لا يُطلَق إلا إذا سَبَقت خُصيُومة (46).

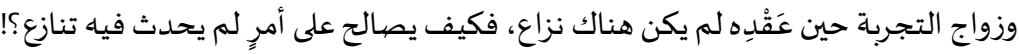

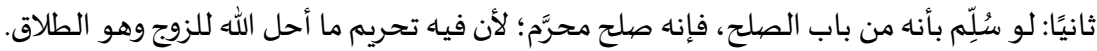

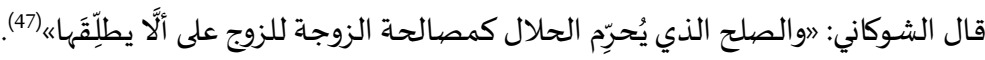

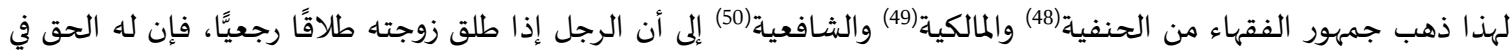

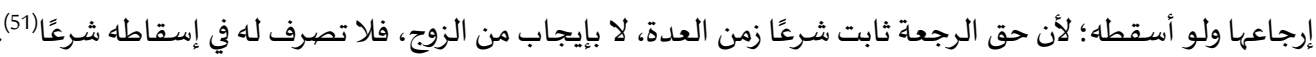

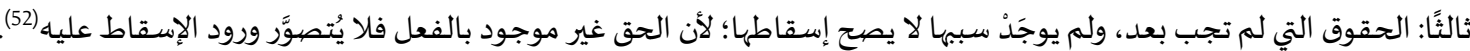

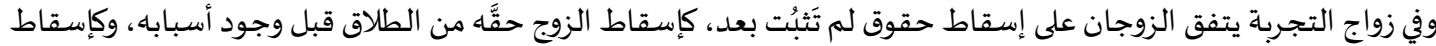

الزوجة حقها من الخلع قبل وجود أسبابه؛ لأن هذا الحق لا يجوز إسقاطه إلا بما أسقطه الله كالثلاث القاضية علية عليه (53.).

$$
\begin{aligned}
& \text { المبحث الثالث: تكييفه على أنه عقد متعة } \\
& \text { المطلب الأوَّلّ: بيان التكييف: } \\
& \text { بيانه: يمكن أن يُخرَّج زواج التجربة على أنهان نكاح متعة (54). }
\end{aligned}
$$

وذلك أنهاه يُنََّّ في العقد على مدة محددة يعلمها الزوجان، وبعد انقضائها يُنظَر في نجاح الحياة الزوجية، وبعد تقييمها بعدم

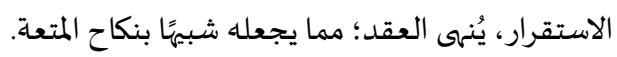

$$
\text { جاء في فتوى الأزهر ما يشير إلى هذا المعنى: }
$$

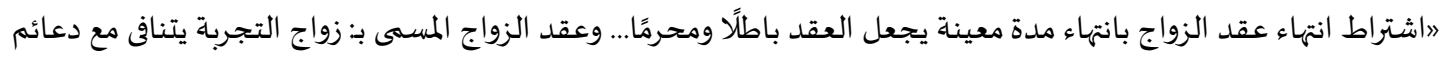
منظومة الزواج في الإسلام ويتصادم مع أحكامه ومقاصدهه، إضافةً إلى ما فياه من امتهان للمرأة وعدم صهون لكرامتها وكرامة أهلها...

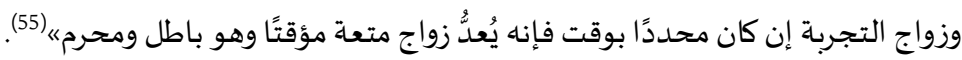
كما أن لفظ (التجربة) يُشعِر بما يؤدياء لفظ (المتعقة) من معنًى. المطلب الثَّاني: الآثار المترتبة على التكييف:

$$
\text { يترتب على هذا التكييف آثار ، منها: }
$$

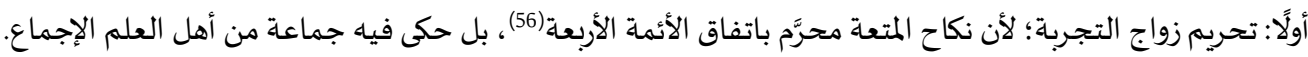

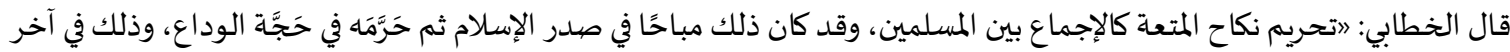

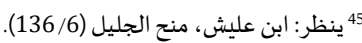

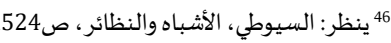

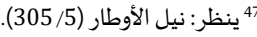

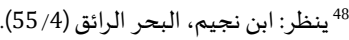

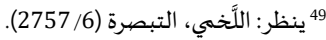

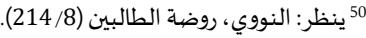

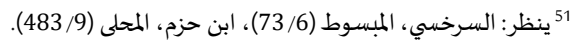

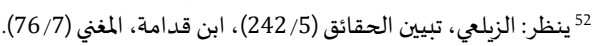

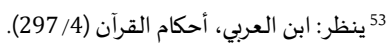

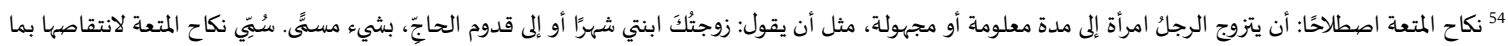
بعطيها، وانتفاعه بقضاء شهوته.

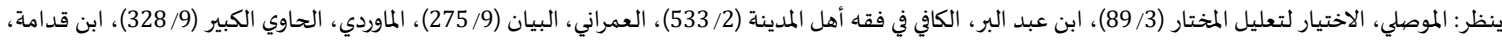

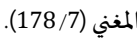
53521/ArticleID/7989waal/ArtMID/7www.azhar.eg/fatwacenter/fatwa/a 5نظر: مركز الأزهر العالمي للفتوى الإلكترونية على شبكة الإنترنت كينظر المرجع قبل السابق. 


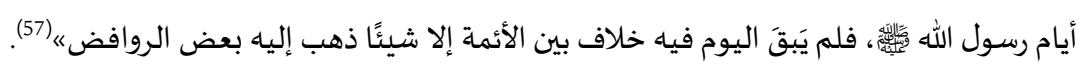

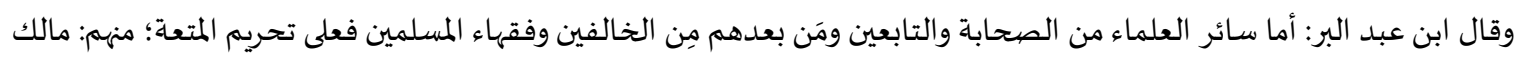
في أهل المدينة، والثوري وأبو حنيفة في أهل الكوفة، والشافعي فيمن سلك سبيله من أهل الحديث والفقها والنظر بالاتفاق والأوزاعي

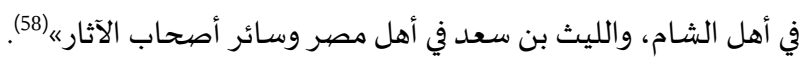
قال الماوردي: قيل: قد رجع ابن عباس عن إباحتها وأظهر تحريمها... ثم رجع عنها فصيار الإجماع برجيت إنوعاه منعقدًا، والخلاف باه مرتفعًا،

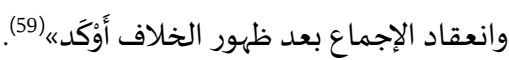

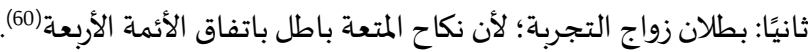

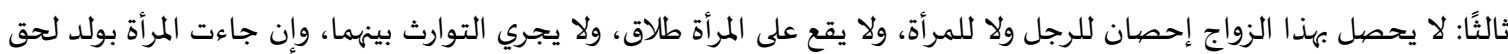

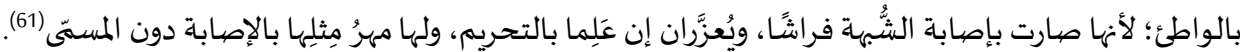

المطلب الثالث: مناقشة التكييف:

هذا التكييف من القوة بمكان، وله حظ من النظر، إلا أنه يَرِد عليه إشكال، وهو: وجود فرق بين نكاح المتعة والتجربة في الصورة والمعنى.

فأما الصورة: فإن نكاح المتعة لا يراد منه الدوام، فهو محدَّد المدة إما بزمن معين أو بتعليقه على وقوع شيء، وبمجرد انتهاء المدة

تنتهي العلاقة بينهما، من دون طلاق.

وأما زواج التجربة فالأصل فيه استمرار العقد ولو بعد مُضِيّ المدة، ولا ينتهي بانتهاء المدة، غاية الأمر أنها جعل للزوقج حقَّ

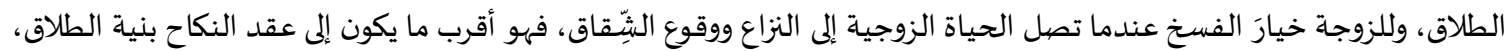

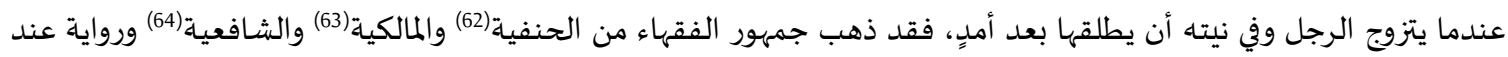
الحنابلة(65) إلى صحتـه.

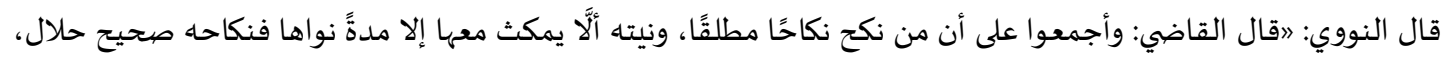

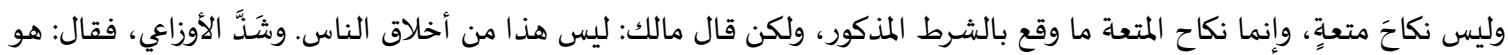

نكاحُ متعبةٍ لا خير فياهی) كما أن التمتع لا يُشترَّط فيه وجود الولي أو الشههود، وزواج التجربة لا يتم إلا بتوفر شروط النكاح.

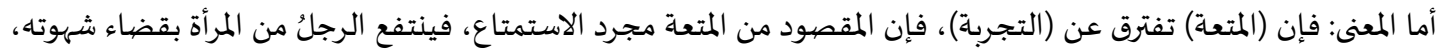

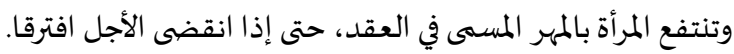

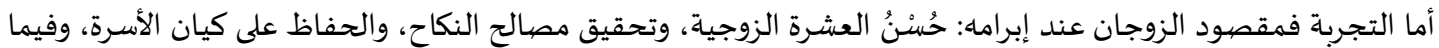

يخص الشروط المنصوص عليها في العقد فالمراد منها: قطع الأسباب المحتمِلة لوقوع النزاع، وبهذا تصير الحياة الزوجية مستقيمةًا.

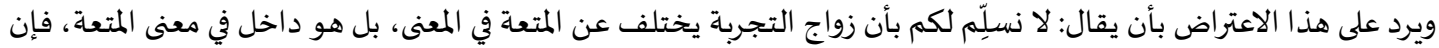

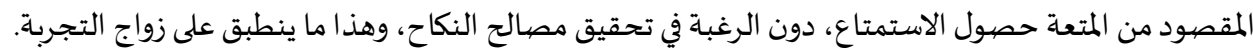

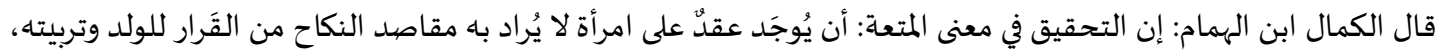

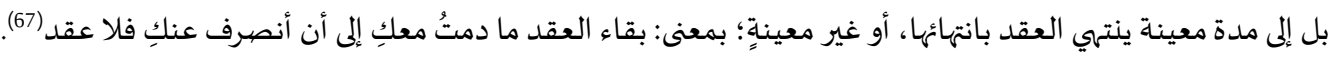

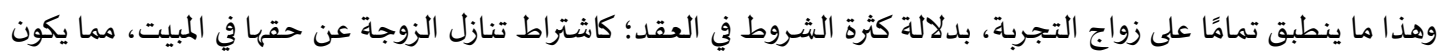

مسوِّغًا لإنهاء العقد لكلا الطرفَيْين.

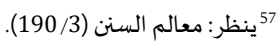

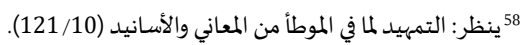
59 ينظر: الماوردي، الحاوي الكبير (250/ 330 - 330 - 332).

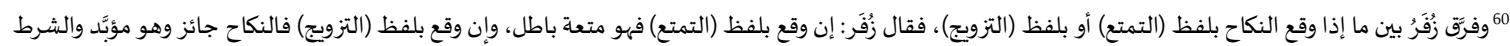

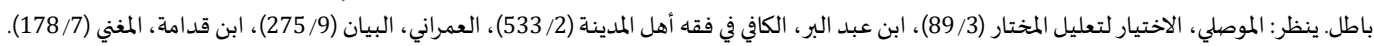

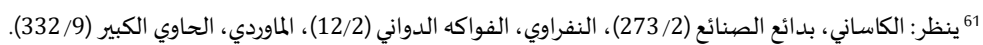

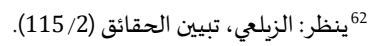

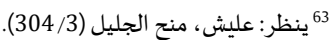
64 ينظر: الماوردي، الحاوي الكبير (179/9 (333).

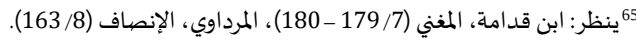

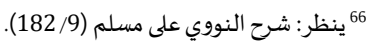
67 ينظر: فتح القدير (247/3) 


\section{المبحث الر ابع: التكييف المختار (العقد صحيح، والشرط باطل)}

المطلب الأوَّل: بيان التكييف: الميان

بيانه: من خلال ما تقدم إيراده من تخريجات ومناقشات، يتبين أن مَوْرِدِ الإشكال في العقد في موضعَينِ اثنَينِ:

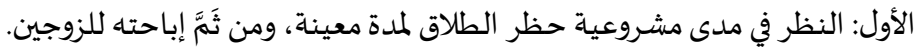

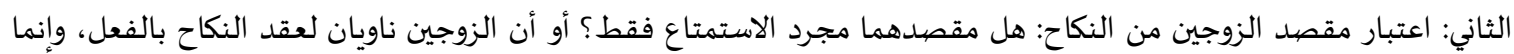

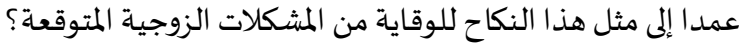

وبتتبع آراء المنظِّرِين لهذا النكاح، وبعد دراسة العقود، يظهر لي أن عقد النكاح مقصود في ذاته، وأن الزوجين أقدما عليه وهما

يريدان تكوين عشرة زوجية شرعية مستقيمة.

وتأسيسًا عليه: يظهر لي أن زواج التجربة عقد صدية صديح؛ لاستيفائه لأركان وشرائط النكاح.

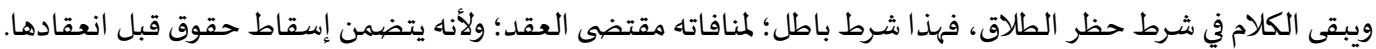

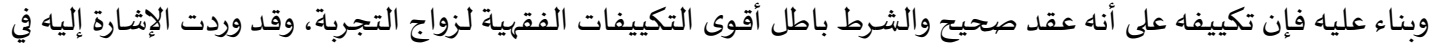
فتوى دار الإفتاء المصرية: اشتراط منع الزوج من حقه في طلاق زوجته في فترة معينة بعد الزواج هو من الشروط الباطلة؛ لأن فيها

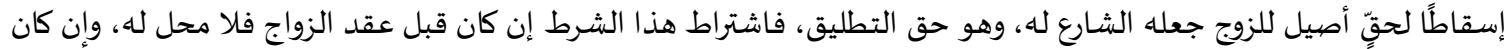

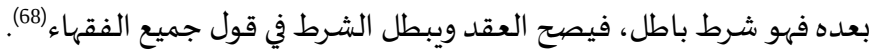
وهنا أحب أن أنبها على أمرَينِي:

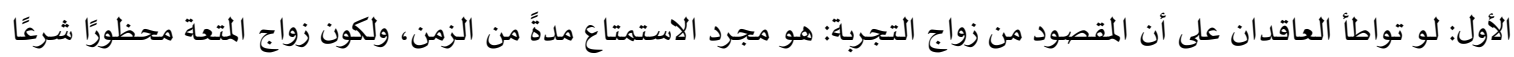

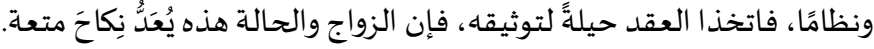

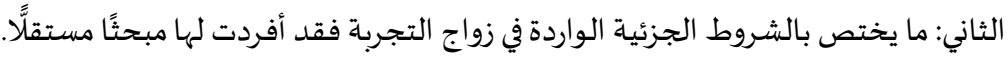
المطلب الثَّاني: الآثار المترتبة على التكييف: مما يترتب على التكييف الآتي:

أولًا: إباحة الطلاق للزوج والخلع للزوجاة عند توفر دواعياه ووجود أسبابه.

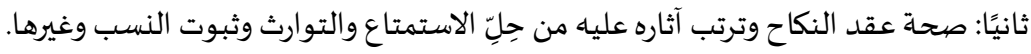

المبحث الخامس: الشروط الجزئية الواردة في العقد

المطلب الأوَّل: اشتراط أن تتنازل المرأة عن حقها في المبيت

وفيه فرعان:

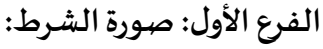

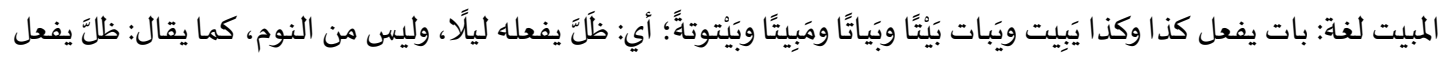

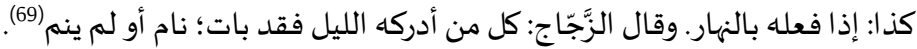

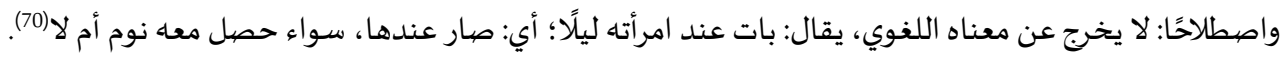

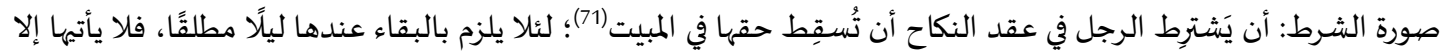

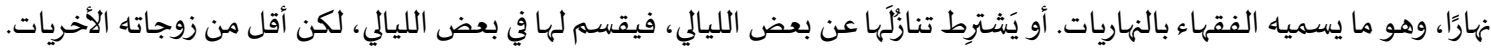

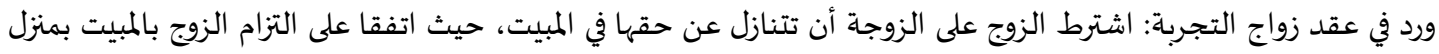

$$
\text { الفرع الثاني: حكمي الخميس والجمعاة. }
$$

اختلف الفقهاء فيما إذا اشترط الزوج على زوجته في العقد أن تُسقِط حقَّها في المبيت كليًّا أو جزئيًا على أقوال: 
القول الأول: يصح العقد والشرط، وهو مذهب الحنفية(72)، ورواية عند الحنابلة (73).

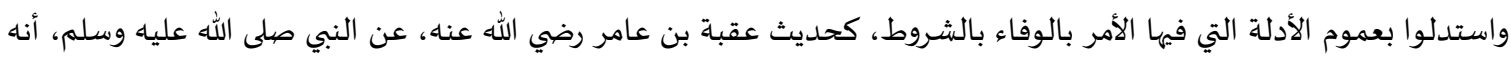

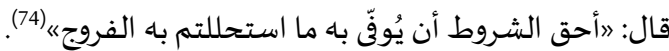

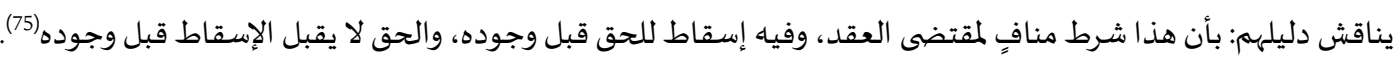

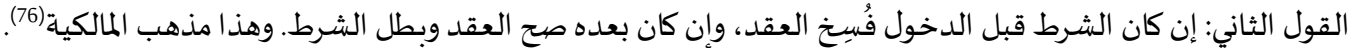

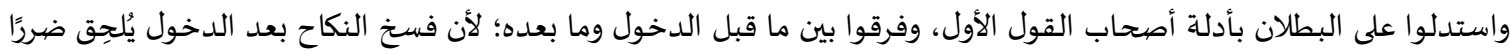

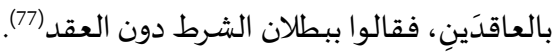

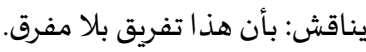
القول الثالث: يصح العقد، ويبطل الشرط. وهذا المشهور من مذهب الشافعية (78)، ومذهب الحنابلة)(79). واستدلوا: بأن الشرط ينافي مقتضى العقد؛ ولأنه يتضمن إسقاط حق يجب وهن بالعقد قبل انعقاده، فلم يصح، كما لو أسقط الشفيع

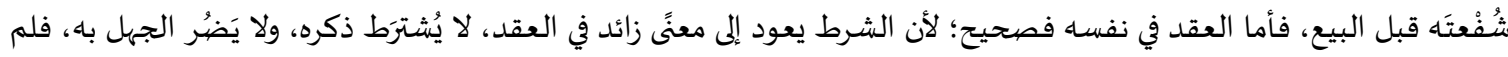

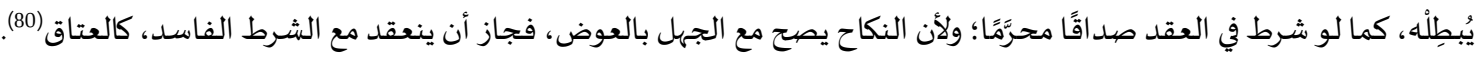

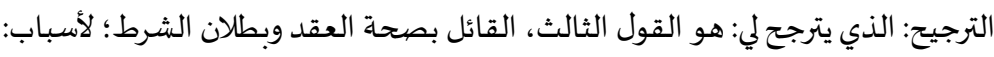

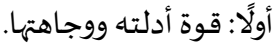

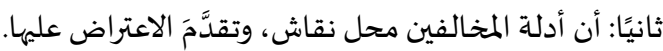
ثالثًا: أن فياه جمعًا بين الأدلة.

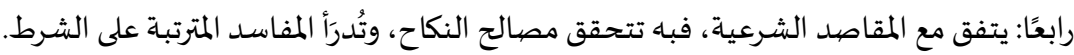

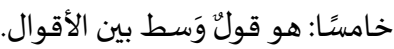
الأثر المترتب على الشرط: بطلان شرط الزوج على زوجته في العقد أن تُسقِطَ حقَّها في المبيت.

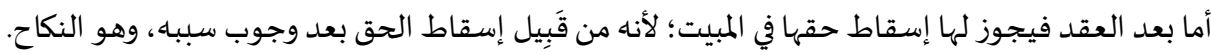

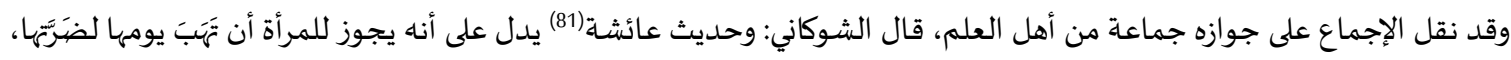
وهو مُجمَع عليه كما في 》البحرب" (82). المطلب الثاني: اشتراط أحد الزوجين على الآخر السماح له بالاطلاع على معلوماته الخاصهة وفياء فرعان:

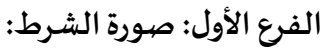
أن تشترط الزوجة في العقد أن يُؤذَنَ لها في اطِّلاعها على المعلومات والحسـابات المالية والشخصية للزوج، واشتراط الزوج الاطِّلاع

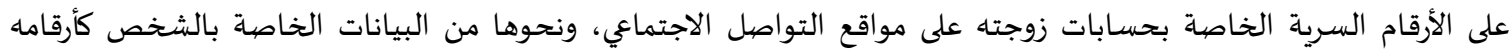
المصرفية وسجله الطبي ومراسلاته السرية. ورد في ضمن شروط عقد زواج التجربة: حق الزوج في الإِّلاع على الأرقام السرية الخاصة بحسـاباتها على مواقع التواصل

(66/5) ينظر: العيني، البناية شرح الهداية (65/7) 733 ينظر: ابن قدامة، المغني (95/7). تقند

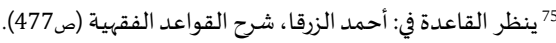

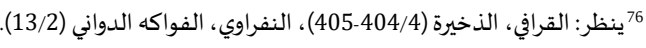
أهذا ما يفهم من أقوالهم. ينظر: المرجع السابق.

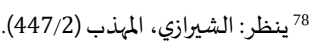

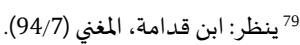

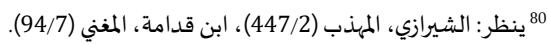

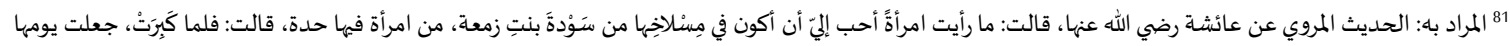

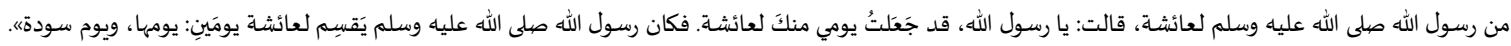

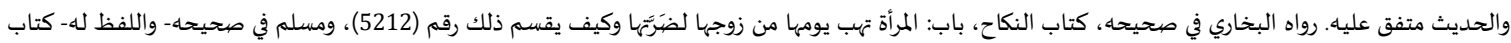


الاجتماعي دون رفض منها. وحق الزوجة في الإِّلاع على المعلومات والحسابات المالية والشخصية للزوج، سواء كانت هذه الحسابات بنكيةً أو إلكترونيةً.

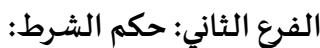

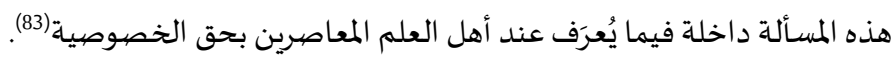

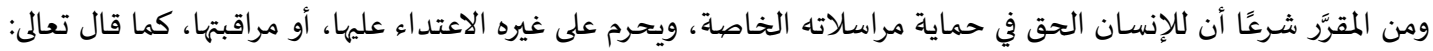

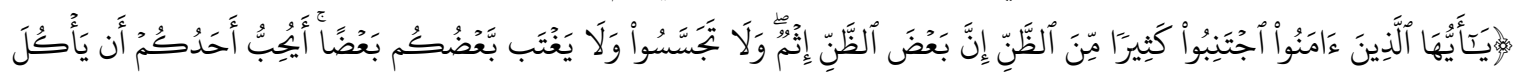

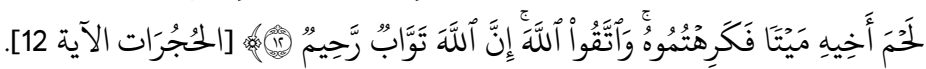

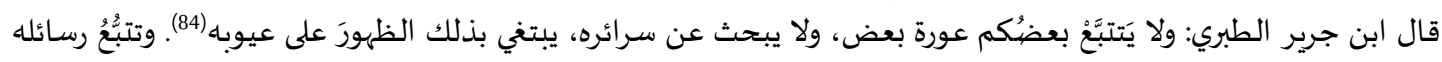
داخلق في هذا المعنى. إذا تقرر هذا، يبقى عندنا تساؤل، وهو: ما الحكم لو شُرط على أحد الزوجين إسقاط حقه في الخصوصية والسماح للطرف

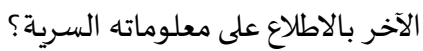
الذي يظهر لي أن الشرط صحيح؛ لأن الأصل في الشروط الصحاة. ويُكيَّف على أنها إسقاط لحق غير مالي.

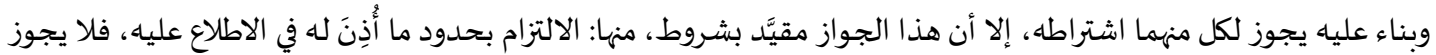

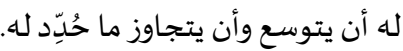

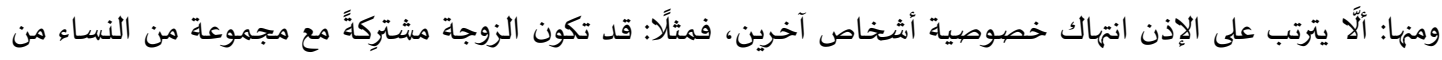

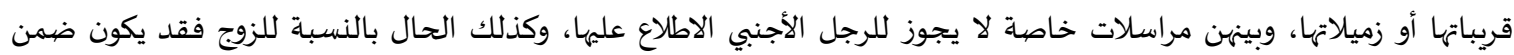

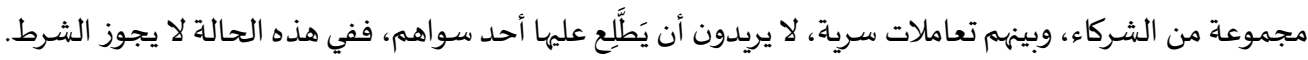

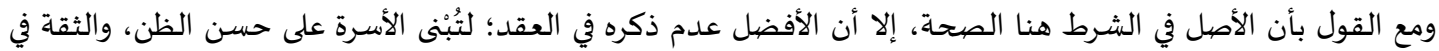

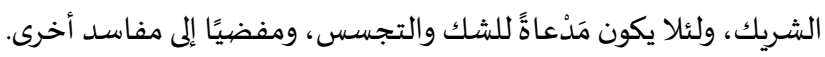

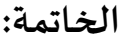
وتشتمل على أهمِّم النَّتائج والتَّوصيَّات.

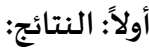

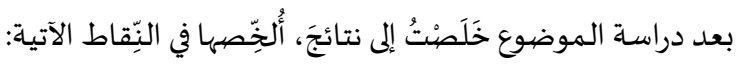

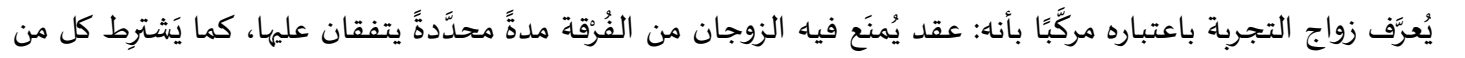

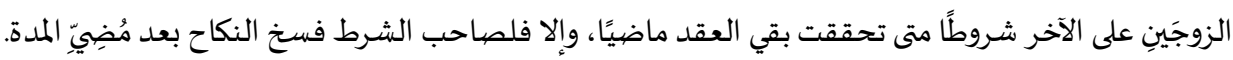
عقد زواج التجربة يتميز عن غيره من أنواع الأنكحة بالآتي:

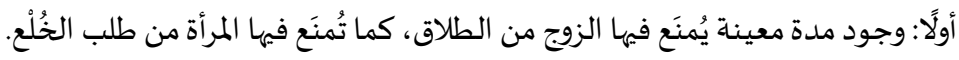

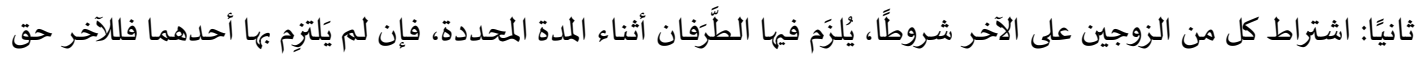

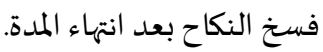
ثالثًا: المقصد من وضع العقد بعد انهذه المدة الصيغة: حَلُّ الخلافات الزوجية لدى حديثي الزواج، بهدف استمرار كيان الأسرة، كما قرره أصحاب فكرة زواج التجربة.

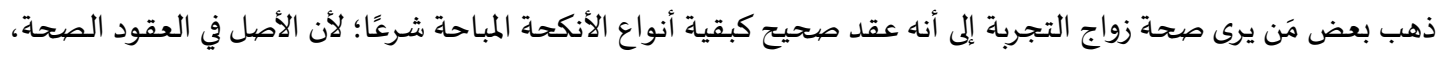

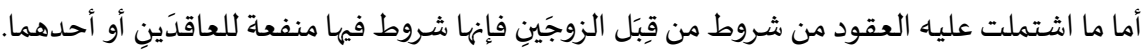
وهذا التكييف ضعيف من وجوه، أبرزها:

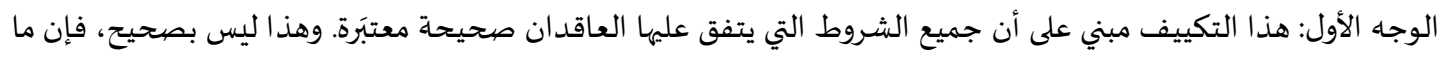

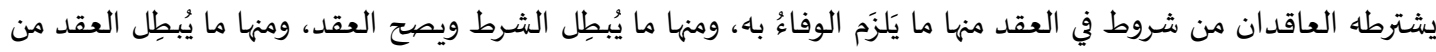

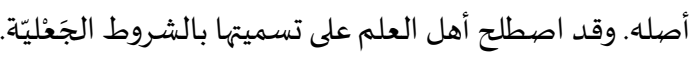
الوجه الثاني: أن زواج التجربة يشتمل على شروط محظورة، منها: مَنْعُ الزوج من الطلاق مدةً ولو وُجِدت أسبابه، ومَنْعُ الزوجة 


$$
\text { من الخُلْع ولو وُجِد المسنوّغ. }
$$

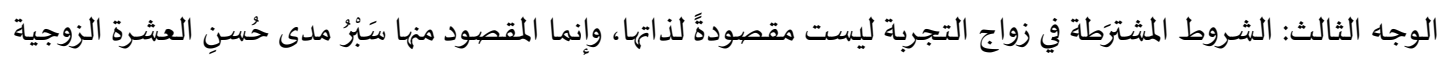

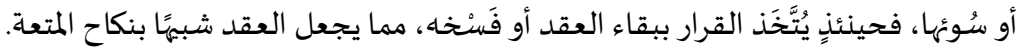

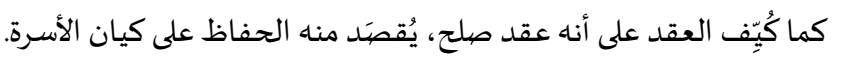

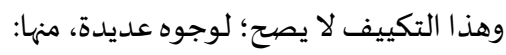

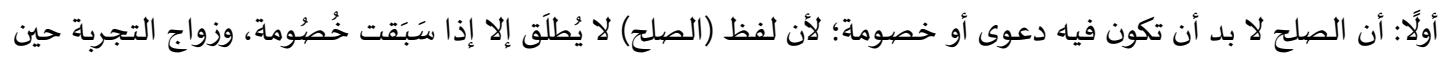

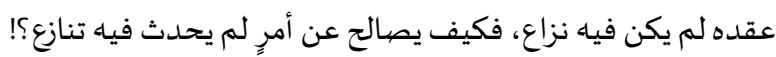

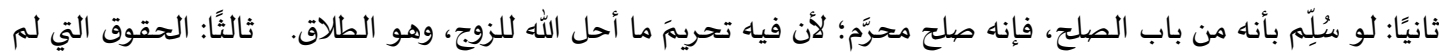
تجب بعدُ ولم يوجَدْ سبيها لا يصحَ إسقاطها.

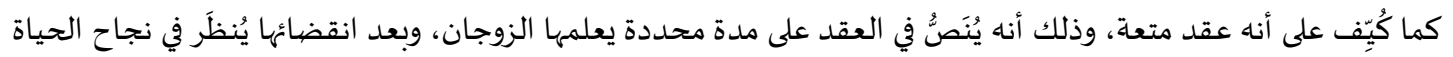

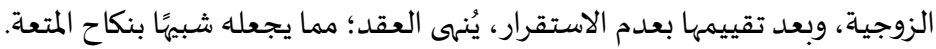

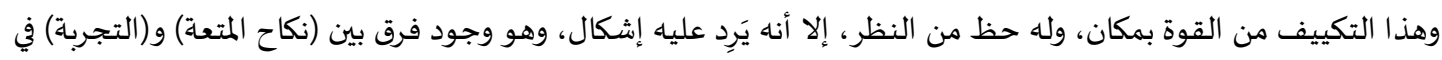

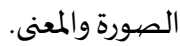

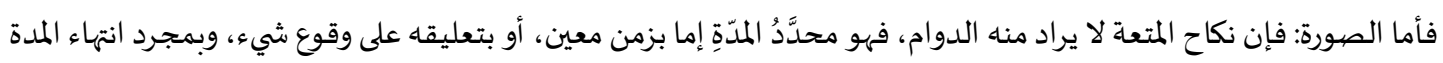

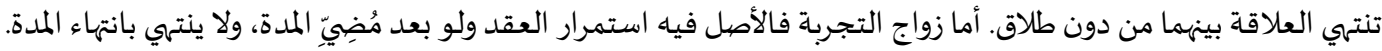

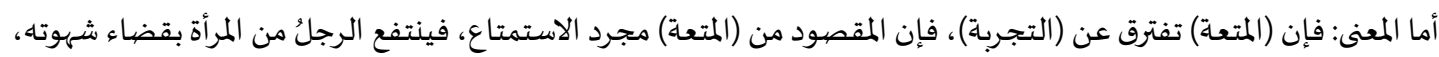

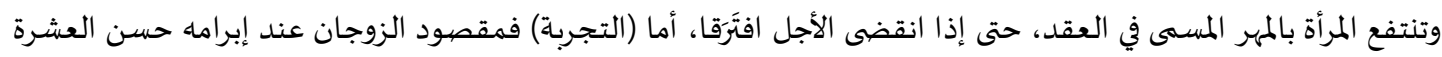

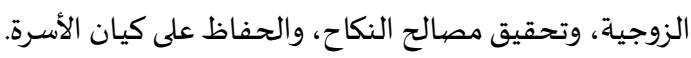

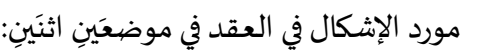

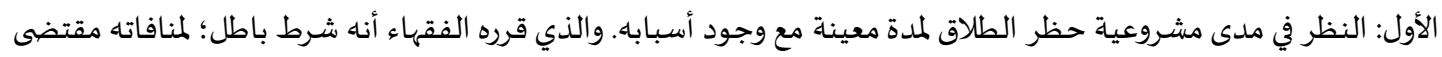

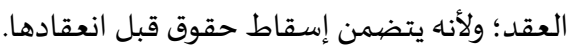

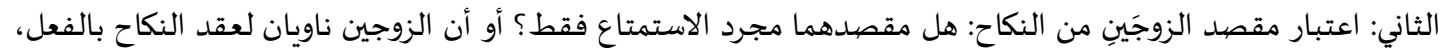

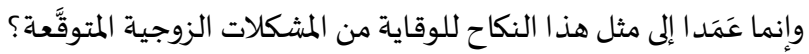

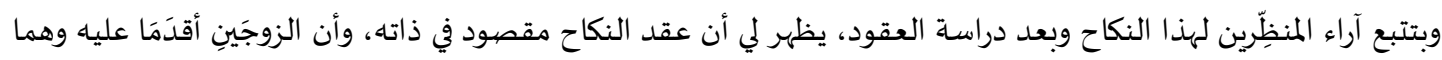

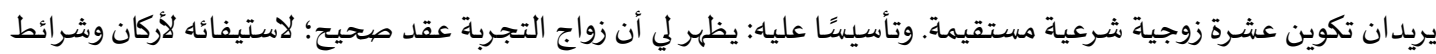
النكاح. وبناء عليه فإن تكييفه على أنه عقد صحيح والشرط باطل أقوى التكييفات الفقهية لزواج التجربة.

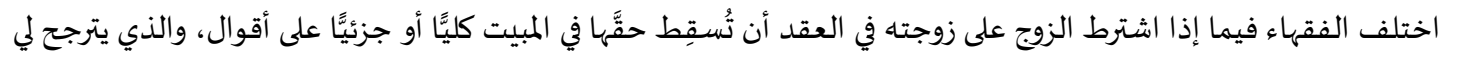

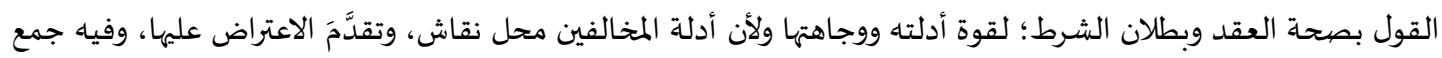

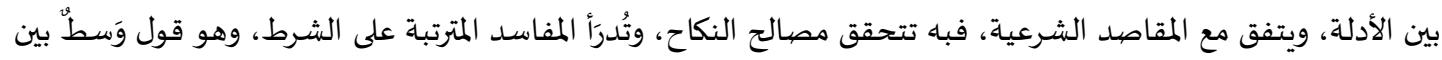
الأقوال. - الان. وحينئذٍ يترتب عليه: بطلان شرط الزوج على زوجته في العقد أن تُسقِط حقَّها في المبيت. أما بعد العقد فيجوز لها إسقاط حقها في

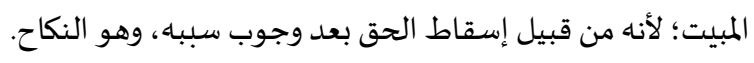

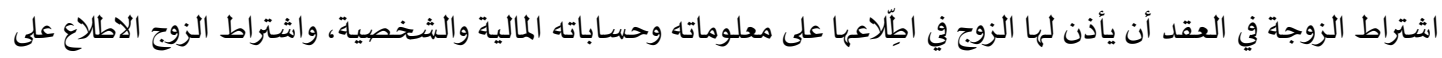

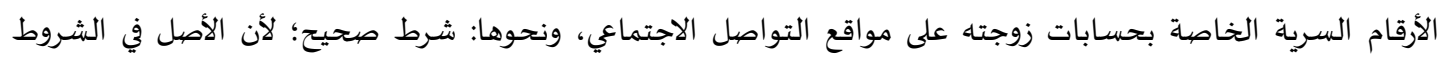

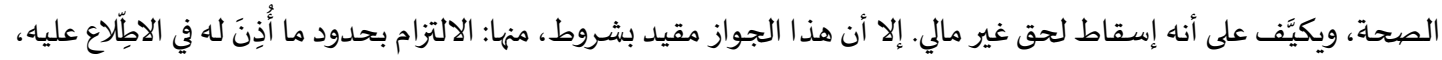

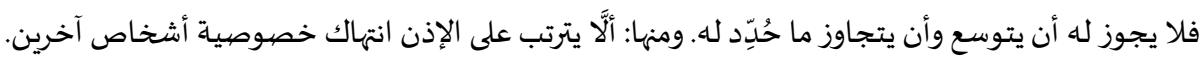
ثانياً: التوصيات: وأخيرًا يوصي الباحث بالآتي: أولَا: الاهتمام بإنشاء مراكز متخصصية، تُعنى بإقامة برامج التأهيل للزواج؛ لتحقيق روابط زوجية ناجحة، وتعمل على إشاعة روح التفاهم بين الزوجَينِ. 
ثانيًا: أهمية دراسة ظاهرة الطلاق في وقتنا الحالي؛ للوقوف على أسباهها ومعالجتها.

ثالثًا: تسهيل وتسريع آلية التواصل بين أفراد المجتمع من جهاة، وبين هيئات ودور الإفتاء ومراكز الاستشارات الأسرية من جهاة

أخرى؛ لحل النزاعات الأسرية قبل استعصيائها.

رابعًا: ضرورة دراسـة المبادرات المجتمعية وتقييمها من جهات مختصية بهذا الشأن قبل تنفيذها.

خامسًا: الحذر من الدعوات التي تروّج لمادة رخيصة تخالف المبادئ الإسلامية والقيم الاجتماعية، بهدف المتاجرة وتحقيق

الشهرة.

المراجع:

1. البابرتي، محمد بن محمد بن محمود. العناية شسح الهد/ية. مطبوع بهامش: فتح القدير للكمال بن الهمام، الطبعة الأولى، شركة

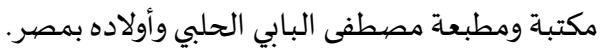

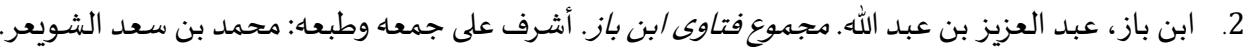

3. البخاري، محمد بن إسماعيل. صححيح البخاري. تحقيق: جماعة من العلماء الطبعة: السلطانية، بالمطبعة الكبرى الأميرية،

ببولاق مصر.

4. البهوتي، منصور بن يونس (1414ه). شـرح منتهى الإراد/ت - المسسى "دقائق أولي النهى لشَح المنتهى". الطبعة: الأولى، عالم

الكتب - بيروت.

5. ابن تيمية. مجموع الفتاوى. جمعها: عبد الرحمن بن محمد بن قاسم، مجمع الملك فهد لطباعة المصحف الشريف.

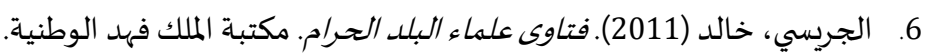

7.

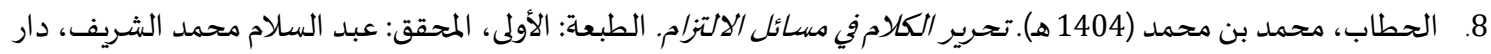

الغرب الإسلامي، بيروت - لبنان.

9. الخضير، فهد بن عبد العزيز. الشروط الجعلية في عقود التوثيق. بحث تكميلي لنيل درجة الماجستير بالمعهد العالي للقضاء.

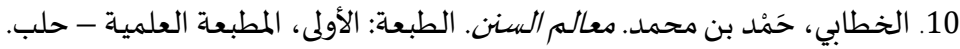

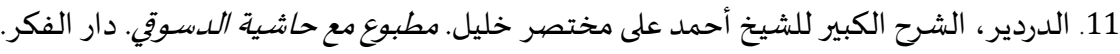

12. ابن رشد الحفيد، محمد بن أحمد (1425ه). بداية المجتهد ونهاية المقتصديد، دار الحديث معيث - القاهرة.

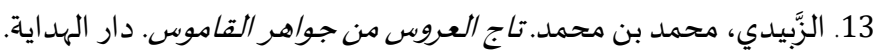

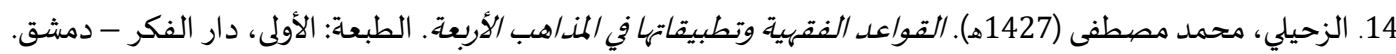

15. الزرقا، أحمد بن محمد. شسح القواعد الفقهية. صحححه وعلق عليه: مصطفى أحمد، الناشر: دار القلم - دمشق، الطبعة:

الثانية.

16. الزمانان، خلود (2017). شروط عقد النكاح في الفقه الإسلامي واختيارات قانون الأحوال الشخصية الكويتي مع بعض القوانين

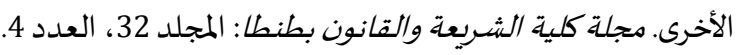

17. الزيلعي، عثمان بن علي. تبيين الحقائق شرح كنز الدقائق مع حاشية شهاب الدين أحمد بن محمد الثيّلْبِيّ. الطبعة: الأولى، المطبعة الكبرى الأميرية - بولاق، القاهرة.

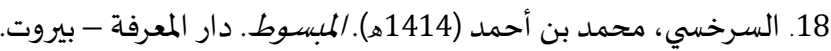

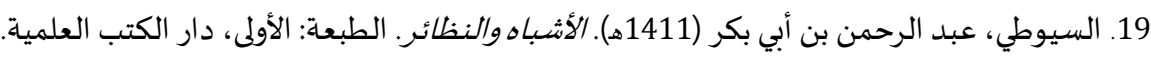

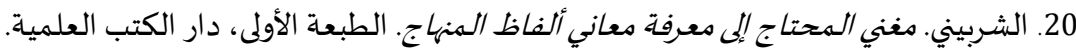

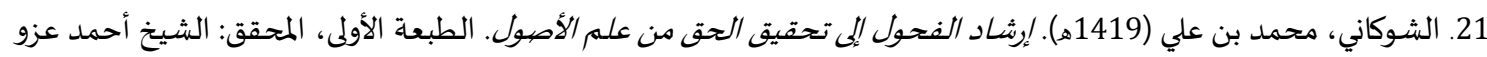

عناية، دار الكتاب العربي.

22. الشوكاني، محمد بن علي (1413هـ). نيل الأوطار. الطبعة: الأولى، تحقيق: عصام الدين الصبابطي، دار الحديث، مصر.

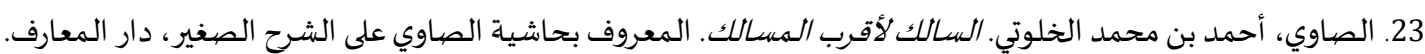

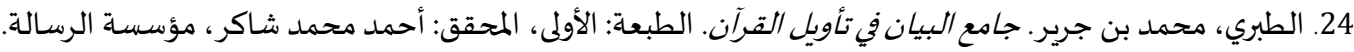

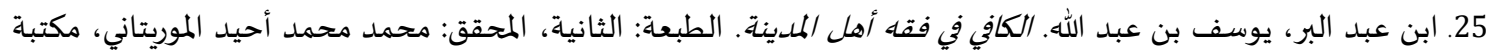

الرياض الحديثة، الرياض. 
26. ابن عبد البر، يوسف بن عبد الله. التمهيد لما في الموطأ من المعاني والأسانيل. تحقيق: مصطفى بن أحمد العلوي، محمد عبد

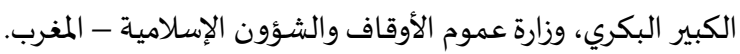

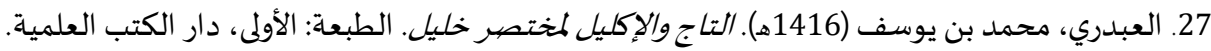

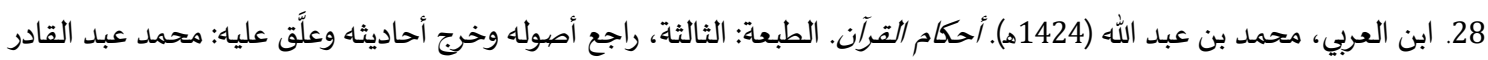
عطا، دار الكتب العلمية، بيروت - لبنان.

29. ابن عرفة، محمد بن محمد (1435ه). المختصر الفقهي. الطبعة: الأولى، المحقق: د. حافظ عبد الرحمن محمد خير، مؤسسة خلف أحمد الخبتور للأعمال الخيرية.

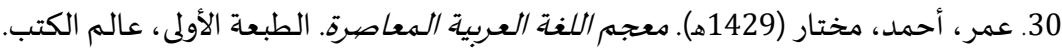

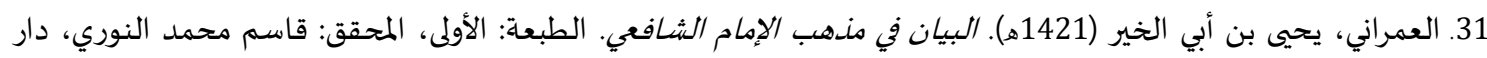
المنهاج - جدة. 32. العوفي والمارني. الشـرط الجعلي وآثاره الفقهية في عقد النكاح: دراسة تحليلية. 33. العينى، محمود بن أحمد (1420ه). البناية شرح الهد/ية. الطبعة: الأولى، دار الكتب العلمية - بيروت، لبنان. 34 35. القرافي، أحمد بن إدريس (1994). النخيرة. الطبعة: الأولى، دار الغرب الإسلامي - بيروت.

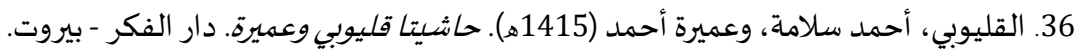

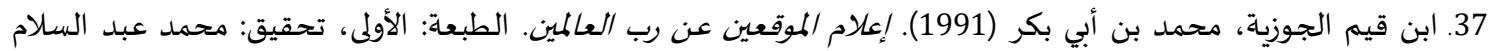
إبراهيم، دار الكتب العلمية - ييروت. 38. القونوي، قاسم بن عبد الله (2004). أنيس الفقهاء في تعبيفات الألفاظ المتداولة بين الفقهاء. المحقق: يحيى حسن مراد، دار الكتب العلمية. 39. النسـفي، عبد الله بن أحمد (2011). كنز الدقائق. المحقق: أ. د. سائد بكداش، الطبعة الأولى، دار البشائر الإسلامية، دار السراج.

40. المرداوي. الإنصاف في معرفة الراجح من الخلاف. الطبعة الثانية، دار إحياء التراث العربي. 41. مسلم بن الحجاج (1419ه). صحيح مسلم. المحقق: محمد فؤاد عبد الباقي، دار إحياء الكتب العربية.

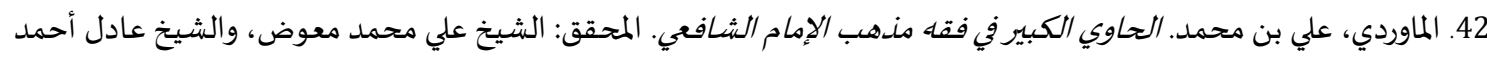
عبد الموجود، الطبعة: الأولى، دار الكتب العلمياة، بيروت - لبنان.

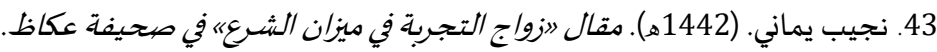

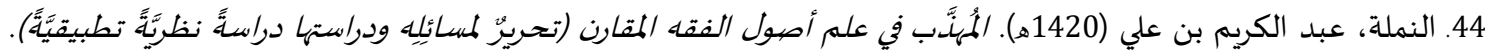

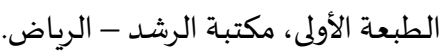
45. الكاساني، أبو بكر بن مسعود. (1406هـ). بدائع الصنائع في ترتيب الثـرائع. الطبعة: الثانية، دار الكتب العلمية. 46. اللجنة الدائمة للبحوث العلمية والإفتاء: فتاوى اللجنة الدائمة جمع وترتيب: أحمد بن عبد الرزاق الدويش، رئاسة إدارة البحوث العلمية والإفتاء. 47. اللخمي، علي بن محمد (1432هـ). التبصرة. الطبعة: الأولى، دراسة وتحقيق: الدكتور أحمد عبد الكريم نجيب، وزارة الأوقاف والشؤون الإسلامية بقطر.

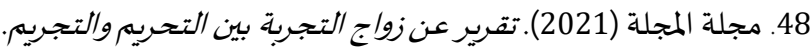

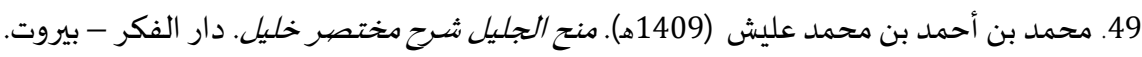
50. مركز الأزهر العالمي للفتوى الإلكترونية على شبكة الإنترنت. www.azhar.eg/fatwacenter/fatwa/a7waal/ArtMID/7989/ArticleID/53521 51. المركز الإعلامي بدار الإفتاء المصرية على شبكة الإنترنت. بتاريخ 2021/1/19م. https://www.facebook.com/EgyptDarAllfta?fref=nf 52. المطلق، نورة بنت عبد الله (1435ه). الشروط التي تَشترِطها المرأة في عقد النكاح. مجلحة العدل: العدد 65.

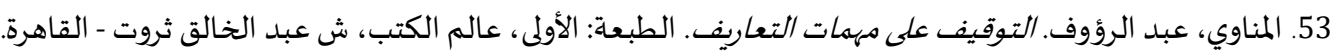
54. ابن منظور، محمد بن مكرم (1414ه). لسان العرب. الحواشي: لليازجي وجماعاة من اللغويين، الطبعة: الثالثة، دار صادر - 
55. الموصلي، عبد الله بن محمود. الاختيار لتعليل المختار. عليها تعليقات: الشيخ محمود أبو دقيقة، مطبعة الحلبي - القاهرة.

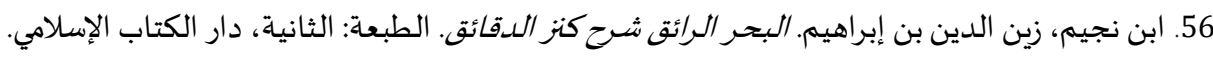

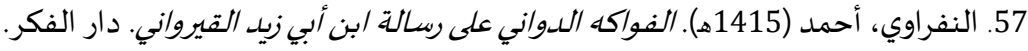

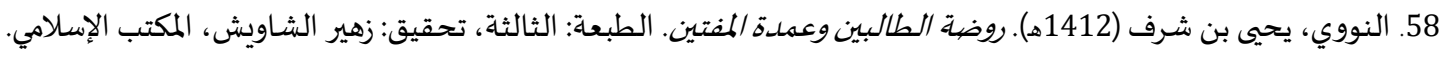
59. النووي، يحيى بن شرف. المنهاج شرح صحيح مسلم بن الحجاج. الطبعة: الثانية، دار إحياء التراث العربي - بيروت.

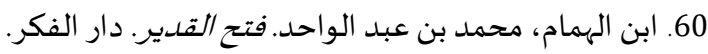

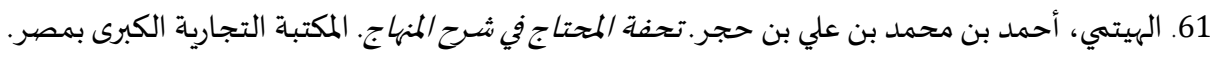


المجلة الدولية للدراسـات الإسلامية المتخصصية

International Journal of Specialized Islamic Studies (SIS)

www.refaad.com

Journal Homepage: https://www.refaad.com/views/SIS/Home.aspx

ISSN: 2617-6246(Online) 2617-6238(Print)

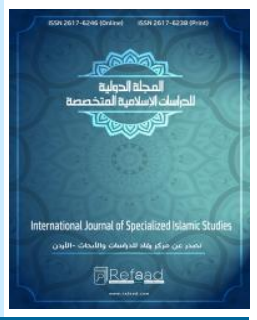

\title{
Trial marriage: jurisprudential conditioning and judgments
}

\author{
Bandar Saqr Al Dhiyabi \\ Associate professor, Department of Sharia, College of Sharia and Regulations \\ University of Tabuk, KSA \\ balthiabi@ut.edu.sa
}

Received: 9/10/2021 Revised: 24/10/2021 Accepted: 11/11/2021 DOI: https://doi.org/10.31559/SIS2021.6.3.4

\begin{abstract}
I discussed the definition of a trial marriage which is defined as a contract in which the spouses are prohibited from separating for a specific period to be agreed upon, and each spouse stipulates conditions to the other when the contract is fulfilled. The contract remains in the past, and the owner of the condition has the right to annul the marriage after the expiration of the contract. This paper also emphasized its jurisprudential modifications which include the fact that it is a lawful contract with important stipulations, a contract of peace, and a contract of pleasure void. It mentioned the following terms in addition to studying some of the contract's partial conditions. Then I suggested a number of things including: a desire to establish specialized centers for the establishment of marriage rehabilitation programs as well as facilitating and speeding up the communication mechanism between members of society on the one hand, and bodies and houses of fatwas and family counseling centers on the other in addition to the importance of studying and analyzing community projects from responsible authorities in this regard before implementing them, and the significance of resolving family issues before they become difficult Also, one should be wary of appeals that promote low-cost merchandise that contradicts Islamic beliefs and societal values in the name of profit and fame.
\end{abstract}

Keywords: Trial marriage; (conditions of marriage); jurisprudential conditioning.

\section{References:}

1. Abn 'bd Albr, Ywsf Bn 'bd Allh. Alkafy Fy Fqh Ahl Almdynh. Altb'h: Althanyh, Almhqq: Mhmd Mhmd Ahyd Almwrytany, Mktbt Alryad Alhdythh, Alryad.

2. Abn 'bd Albr, Ywsf Bn 'bd Allh. Altmhyd Lma Fy Almwta Mn Alm'any Walasanyd. Thqyq: Mstfa Bn Ahmd Al'lwy, Mhmd 'bd Alkbyr Albkry, Wzart 'mwm Alawqaf Walsh'wn Aleslamyh - Almghrb.

3. Al'bdry, Mhmd Bn Ywsf (1416h). Altaj Waleklyl Lmkhtsr Khlyl. Altb'h: Alawla, Dar Alktb Al'lmyh.

4. Abn Al'rby, Mhmd Bn 'bd Allh (1424h). Ahkam Alqran. Altb'h: Althalthh, Raj' Aswlh Wkhrj Ahadythh W'lq 'lyh: Mhmd 'bd Alqadr 'ta, Dar Alktb Al'lmyh, Byrwt - Lbnan.

5. Abn 'rfh, Mhmd Bn Mhmd (1435h). Almkhtsr Alfqhy. Altb'h: Alawla, Almhqq: D. Hafz 'bd Alrhmn Mhmd Khyr, M'sstKhlf Ahmd Alkhbtwr Lla'mal Alkhyryh.

6. 'mr, Ahmd, Mkhtar (1429h). M'jm Allghh Al'rbyh Alm'asrh. Altb'h Alawla, 'alm Alktb.

7. Albabrty, Mhmd Bn Mhmd Bn Mhmwd. Al'nayh Shrh Alhdayh. Mtbw' Bhamsh: Fth Alqdyr Llkmal Bn Alhmam, Altb'h Alawla, Shrkt Mktbt Wmtb't Mstfa Albaby Alhlby Wawladh Bmsr.

8. Abn Baz, 'bd Al'zyz Bn 'bd Allh. Mjmw' Ftawa Abn Baz. Ashrf 'la Jm't Wtb'h: Mhmd Bn S'd Alshwy'r.

9. Albhwty, Mnswr Bn Ywns (1414h). Shrh Mntha Aleradat - Almsma «Dqa'q Awly Alnha Lshrh Almntha». Altb'h: Alawla, 'alm Alktb - Byrwt.

10. Albkhary, Mhmd Bn Esma'yl. Shyh Albkhary. Thqyq: Jma't Mn Al'lma' Altb'h: Alsltanyh, Balmtb'h Alkbra Alamyryh, Bbwlaq Msr.

11. Aldrdyr, Alshrh Alkbyr Llshykh Ahmd 'la Mkhtsr Khlyl. Mtbw' M' Hashyh Aldswqy. Dar Alfkr.

12. Abn Tymyh. Mjmw' Alftawa. Jm'ha: 'bd Alrhmn Bn Mhmd Bn Qasm, Mjm' Almlk Fhd Ltba'h Almshf Alshryf.

المجلة الدولية للدراسات الإسلامية المتخصصية- المجلد6، العدد3- 2021، ص: 198- 215 
13. Alhtab, Mhmd Bn Mhmd (1404 H). Thryr Alklam Fy Msa'l Alaltzam. Altb'h: Alawla, Almhqq: 'bd Alslam Mhmd Alshryf, Dar Alghrb Aleslamy, Byrwt - Lbnan.

14. Abn Hzm Alzahry, 'ly Bn Ahmd. Almhla Balathar. Dar Alfkr.

15. Aljrysy, Khald (2011). Ftawa 'Ima' Albld Alhram. Mktbt Almlk Fhd Alwtnyh.

16. Alkhdyr, Fhd Bn 'bd Al'zyz. Alshrwt Alj'lyh Fy 'qwd Altwthyq. Bhth Tkmyly Lnyl Drjt Almajstyr Balm'hd Al'aly Llqda'.

17. Alkhtaby, Hmơd Bn Mhmd. M'alm Alsnn. Altb'h: Alawla, Almtb'h Al'lmyh - Hlb.

18. Abn Rshd Alhfyd, Mhmd Bn Ahmd (1425h). Bdayh Almjthd Wnhayh Almqtsd, Dar Alhdyth - Alqahrh.

19. Alsawy, Ahmd Bn Mhmd Alkhlwty. Alsalk Laqrb Almsalk. Alm'rwf Bhashyh Alsawy 'la Alshrh Alsghyr, Dar Alm'arf.

20. Alshrbyny. Mghny Almhtaj Ela M'rft M'any Alfaz Almnhaj. Altb'h Alawla, Dar Alktb Al'lmyh.

21. Alshwkany, Mhmd Bn 'ly (1419h). Ershad Alfhwl Ela Thqyq Alhq Mn 'Im Alaswl. Altb'h Alawla, Almhqq: Alshykh Ahmd 'zw 'nayh, Dar Alktab Al'rby.

22. Alshwkany, Mhmd Bn 'ly (1413h). Nyl Alawtar. Altb'h: Alawla, Thqyq: 'sam Aldyn Alsbabty, Dar Alhdyth, Msr.

23. Alsrkhsy, Mhmd Bn Ahmd (1414h). Almbswt. Dar Alm'rfh - Byrwt.

24. Alsywty, 'bd Alrhmn Bn Aby Bkr (1411h). Alashbah Walnza'r. Altb'h: Alawla, Dar Alktb Al'lmyh.

25. Altbry, Mhmd Bn Jryr. Jam' Albyan Fy Tawyl Alqran. Altb'h: Alawla, Almhqq: Ahmd Mhmd Shakr, M'sst Alrsalh.

26. Alzbydy, Mhmd Bn Mhmd. Taj Al'rws Mn Jwahr Alqamws. Dar Alhdayh.

27. Alzhyly, Mhmd Mstfa (1427h). Alqwa'd Alfqhyh Wttbyqatha Fy Almdahb Alarb'h. Altb'h: Alawla, Dar Alfkr - Dmshq.

28. Alzmanan, Khlwd (2017). Shrwt 'qd Aln 5 Ah Fy Alfqh Aleslamy Wakhtyarat Qanwn Alahwal Alshkhsyh Alkwyty M' B'd Alqwanyn Alakhra. Mjlt Klyt Alshry'h Walqanwn Btnta: Almjld 32, Al'dd 4.

29. Alzrqa, Ahmd Bn Mhmd. Shrh Alqwa'd Alfqhyh. Shhh W'lq 'lyh: Mstfa Ahmd, Alnashr: Dar Alqlm - Dmshq, Altb'h: Althanyh.

30. Alzyl'y, 'thman Bn 'ly. Tbyyn Alhqa'q Shrh Knz Aldqa'q M' Hashyh Shhab Aldyn Ahmd Bn Mhmd Alshlby. Altb'h: Alawla, Almtb'h Alkbra Alamyryh - Bwlaq, Alqahrh. 